\title{
NTRC and Chloroplast-Generated Reactive Oxygen Species Regulate Pseudomonas syringae pv. tomato Disease Development in Tomato and Arabidopsis
}

\author{
Yasuhiro Ishiga, Takako Ishiga, Tamding Wangdi, Kirankumar S. Mysore, and \\ Srinivasa Rao Uppalapati
}

Plant Biology Division, Samuel Roberts Noble Foundation, Ardmore, OK 73401, U.S.A.

Submitted 20 May 2011. Accepted 10 November 2011.

\begin{abstract}
Coronatine (COR)-producing pathovars of Pseudomonas syringae, including pvs. tomato, maculicola, and glycinea, cause important diseases on tomato, crucifers, and soybean, respectively, and produce symptoms with necrotic lesions surrounded by chlorosis. The chlorosis is mainly attributed to COR. However, the significance of COR-induced chlorosis in localized lesion development and the molecular basis of disease-associated cell death is largely unknown. To identify host (chloroplast) genes that play a role in CORmediated chlorosis, we used a forward genetics approach using Nicotiana benthamiana and virus-induced gene silencing and identified a gene which encodes 2-Cys peroxiredoxin (Prxs) that, when silenced, produced a spreading hypersensitive or necrosis-like phenotype instead of chlorosis after COR application in a COI1-dependent manner. Loss-of-function analysis of Prx and NADPH-dependent thioredoxin reductase $\mathrm{C}(N T R C)$, the central players of a chloroplast redox detoxification system, resulted in spreading accelerated $P$. syringae pv. tomato DC3000 disease-associated cell death with enhanced reactive oxygen species (ROS) accumulation in a COR-dependent manner in tomato and Arabidopsis. Consistent with these results, virulent strain DC3000 suppressed the expression of Prx and NTRC in Arabidopsis and tomato during pathogenesis. However, interestingly, authentic COR suppressed the expression of Prx and NTRC in tomato but not in Arabidopsis, suggesting that COR in conjunction with other effectors may modulate ROS and cell death in different host species. Taken together, these results indicated that NTRC or Prx function as a negative regulator of pathogen-induced cell death in the healthy tissues that surround the lesions, and CORinduced chloroplast-localized ROS play a role in enhancing the disease-associated cell death.
\end{abstract}

Plants are constantly exposed to a wide-range of microorganisms, including potential pathogens in their natural habitats. Therefore, they have evolved innate immune systems that

Current address for T. Wangdi: Yale University School of Medicine, 1 Gilbert Street, New Haven, VT 06510, U.S.A.

Corresponding authors: S. R. Uppalapati; Telephone: +1 580224 6180; Fax: +1 580224 6692; E-mail: sruppalapati@noble.org; and K. S. Mysore; Telephone: +1 580224 6740; Fax: +1 580224 6692; E-mail: ksmysore@noble.org

* The $\boldsymbol{e}$-Xtra logo stands for "electronic extra" and indicates that seven supplementary figures and one supplementary table are published online. sense invading pathogens and activate an array of defense responses to protect themselves. The plant innate immune system consists of two main branches. One is called effector-triggered immunity (ETI) or host-specific resistance based on the genefor-gene theory, which is governed by individual plant resistance genes and their corresponding avirulence $(A v r)$ genes (Ellis et al. 2000). In addition, plants also have a general resistance to almost all host or nonhost pathogens potentially mediated by a resistance mechanism called basal resistance or nonhost resistance, respectively. The primary response of nonhost or basal resistance is the recognition of conserved molecules from microorganisms, called microbe-associated molecular patterns or pathogen-associated molecular patterns (PAMPs), such as flagellin, elongation factor Tu, lipopolysaccharides, peptidoglycans (Gomez-Gomez and Boller 2002; Gust et al. 2007; Segonzac and Zipfel 2011), or chitin (Wan et al. 2008a and b) by plant pattern-recognition receptors, resulting in PAMP-triggered immunity (PTI) (Zipfel 2008). ETI and PTI induce similar innate immune responses, including rapid oxidative burst, callose $(\beta-$ 1,3-glucan) deposition in the cell wall, and the activation of hormone-mediated signaling pathways leading to defense responses (Zhang and Zhou 2010; Zipfel 2008). However, ETItriggered immunity generally includes the induction of a rapid programmed cell death (PCD) known as the hypersensitive response (HR) cell death (Heath 2000).

The HR cell death induced by ETI is the most well-characterized form of plant PCD (Greenberg and Yao 2004). Although the precise role of secondary messengers in HR cell death is still unclear, the most intensively investigated signal for HR cell death is reactive oxygen species (ROS) (Mur et al. 2008). Apoplastic ROS derived from plasma membrane-bound NADPH oxidase is well known to regulate PCD associated with the HR (Mur et al. 2008). In contrast to HR cell death associated with incompatible interactions, the molecular basis of diseaseassociated cell death during compatible interactions is largely unknown. Localized cell death and tissue chlorosis are often associated with disease symptom development during compatible plant-pathogen interactions. Most of our present understanding of the disease-associated cell death is obtained from the genetic analysis of compatible interactions of Pseudomonas syringae pv. tomato DC3000 with Arabidopsis and tomato. It has been shown that a mitogen-activated protein kinase kinase kinase (MAPKKK $\alpha$ ) plays a role in the regulation of diseaseassociated cell death induced by strain DC3000 in tomato (del Pozo et al. 2004). Furthermore, a gene involved in autophagy, ATG6, was shown to be required for the limitation of diseaseassociated cell death induced by strain DC3000 in Arabidopsis (Liu et al. 2005; Patel and Dinesh-Kumar 2008). The bacterial 
speck disease caused by pathovars of $P$. syringae pv. tomato includes the formation of necrotic lesions (cell death) surrounded by diffuse chlorotic halos (Bender et al. 1999; Preston 2000). Disease-associated chlorosis has been attributed mainly to the phytotoxin coronatine (COR) produced by several pathovars of $P$. syringae (Bender et al. 1987, 1998; Uppalapati et al. 2007; Zhao et al. 2003) and a less-characterized chlorosisinducing factor, PSPTO4723 (Munkvold et al. 2009). However, our understanding of the host signaling components exploited by pathogen effectors to cause chlorosis and disease-associated cell death is limited (del Pozo et al. 2004; Greenberg and Yao 2004; Ishiga et al. 2009a and b; Wangdi et al. 2010a). Also, a molecular link between COR-induced chlorosis and diseaseassociated cell death during the necrogenic phase of bacterial speck disease development has not been determined.

COR has structural and functional similarity to jasmonates, including jasmonic acid (JA)-isoleucine (Katsir et al. 2008; Staswick and Tiryaki 2004; Uppalapati et al. 2005; Weiler et al. 1994). Furthermore, the F-box protein COR-insensitive 1/JA-insensitive 1 (COI1/JAI1) was shown to be required for COR signaling in tomato and Arabidopsis (Feys et al. 1994; Katsir et al. 2008; Kloek et al. 2001; Zhao et al. 2003). F-box proteins belonging to an $\mathrm{E}_{3}$ ubiquitin ligase family assemble SCF (Skp1/Cul1/F-box) complexes and play a major role in controlled protein degradation through a ubiquitin/26S proteasome pathway during plant hormone signaling and development (Santner and Estelle, 2009). By mimicking jasmonates, COR stimulates the JA pathway in Arabidopsis and tomato and, thereby, functions to suppress the salicylic acid pathway or closure of stomata, allowing bacteria to reach higher densities in planta (Kloek et al. 2001; Melotto et al. 2006; Uppalapati et al. 2007; Zhao et al. 2003). However, the physiological significance of COR-induced chlorosis in disease development is not completely understood. Recently, we demonstrated that silencing of SGT1 (suppressor of G2 allele of $s k p 1$ ) abolished CORinduced chlorosis. Furthermore, in Arabidopsis, AtSGT1b but not AtSGTla was required for COR responses and P. syringae pv. tomato DC3000 symptom (water-soaked lesion) development, and silencing of $S G T 1$ in tomato resulted in reduction of disease-associated cell death and chlorosis, suggesting a connection between COR-induced chlorosis and cell death (Uppalapati et al. 2010). In addition, COR targets photosynthetic machinery to modulate chloroplast ROS homeostasis in promoting disease-associated cell death during bacterial speck disease of tomato (Ishiga et al. 2009a and b). However, the precise plant targets for COR and a physiological and molecular understanding of localized cell death (bacterial speck) during disease development is not known. Understanding of this process is important for engineering bacterial speck resistance in tomato.

To identify the targets for COR and molecular interaction between COR-induced chlorosis and necrosis, we utilized Nicotiana benthamiana and virus-induced gene silencing (VIGS) to individually reduce the expression of over 4,000 genes, and identified several altered COR response $(A L C)$ genes that caused altered responses to $\mathrm{COR}$ when silenced (Wangdi et al. 2010b). One of these sequences (Nb2F10; ALC2) showed $94 \%$ identity to tobacco (N. tabacum) thioredoxin peroxidase (GenBank accession number AJ309009) (Wangdi et al. 2010b). In this study, we further investigated the role of peroxiredoxin (Prx) or thioredoxin peroxidase and NADPH-dependent thioredoxin reductase C (NTRC) in COR signaling and disease-associated cell death. Our results showed that the loss-of-function of $N T R C$, an electron donor for Prxs in the NADPH-dependent thioredoxin (Trx) system, leads to accelerated ROS accumulation and $P$. syringae pv. tomato DC3000 disease-associated cell death in tomato and Arabidop- sis in a COR-dependent manner, and further indicated that NTRC or Prxs functions as a negative regulator of pathogeninduced cell death and, thereby, limits runaway cell death. Furthermore, $N T R C$-silenced tomato plants showed accelerated disease-associated cell death in response to the fungal pathogen Sclerotinia sclerotiorum. Therefore, our results indicate that chloroplast-generated ROS plays a common role in enhancing the cell death associated with hemibiotrophic and necrotrophic pathogens.

\section{RESULTS}

\section{Prx- and NTRC-silenced $N$. benthamiana and tomato plants show necrosis in response to $\mathrm{COR}$ in a $\mathrm{COI1}$-depndent manner.}

The application of COR to vector control (TRV2::GFP; the green fluorescent protein [GFP] sequence does not have any homology to plant DNA and, therefore, will not cause gene silencing)-inoculated $N$. benthamiana plants resulted in a defined chlorotic halo (Fig. 1A). However, NbALC2/NbPrxsilenced $N$. benthamiana plants which show a very high efficiency of silencing, as confirmed using real-time quantitative reverse-transcription polymerase chain reaction (qRT-PCR) (Supplementary Fig. S1A), produced necrosis upon COR application (Fig. 1A). The necrotic phenotype was associated with early induction and accumulation of higher levels of ROS when compared with the mock control plants (Fig. 1B). These results indicate that COR-induced $\operatorname{ROS}\left(\mathrm{H}_{2} \mathrm{O}_{2}\right)$ overaccumulate in $N b A L C 2 / N b P r x$-silenced plants. Consistent with this hypothesis, externally applied $\mathrm{H}_{2} \mathrm{O}_{2}$ also induced more severe necrotic cell death at lower concentrations in $\mathrm{NbPrx}$-silenced plants compared with the vector control plants (Supplementary Fig. S2). To further test the role of chloroplast-generated ROS in COR signaling, we cloned a fragment of tomato gene encoding SlPrx (SGN-U579709) and NTRC, a more efficient reductant of Prx, SINTRC (SGN U572332), with a very high amount of nucleotide sequence identity between tomato and $N$. benthamiana sequences encoding NTRC (Supplementary Figs. S3 and S4). It has been suggested that a 21-nucleotide stretch of $100 \%$ identity between the heterologous and endogenous gene sequences is not absolutely required to achieve efficient gene silencing using VIGS (Senthil-Kumar et al. 2007); therefore, we used NTRC/Prx coding sequences from tomato to silence ortholog genes in $N$. benthamiana or vice versa. Silencing of SINTRC in $N$. benthamiana resulted in efficient silencing of the endogenous NbNTRC. Application of COR to $N T R C$-silenced $N$. benthamiana resulted in a necrosis-like phenotype (Fig. 1C). These results suggested that COR induces chloroplastic ROS and, in Prx- and NTRC-silenced plants that are compromised in an efficient redox detoxification or homeostasis, COR-induced ROS overaccumulates, leading to necrotic cell death. Interestingly, no runaway cell death phenotype was observed in Prx- or NTRC-silenced $N$. benthamiana plants in response to HR-inducing nonhost pathogens (P. syringae pv. tomato strains DC3000 and T1), ETI (AvrPto), and a PAMP (INF1) (Supplementary Fig. S5).

However, it is important to note that silencing of Prx or $N T R C$ in N. benthamiana resulted in a light-green leaf phenotype. Therefore, one could argue that the COR-induced necrotic phenotype in these plants may result from photobleaching or degradation products of chlorophyll rather than from the direct effects of COR-induced ROS. To rule out this possibility, we applied COR to $N$. benthamiana plants silenced for $\mathrm{ChlH}$, the gene encoding the $\mathrm{H}$ subunit of the magnesium chelatase enzyme. Although $\mathrm{ChlH}$-silenced $N$. benthamiana leaves had very low levels of their respective transcripts and showed reduced chlorophyll content and photobleaching, they failed to 
show necrotic phenotype in response to COR (Fig. 1C). These results confirmed that the yellowish coloration or photobleaching per se does not affect the COR responses, and specific elimination of Prx or NTRC is required for induction of necrosis by COR in $N$. benthamiana.

To better understand the role of chloroplast-generated ROS in bacterial speck disease, we first tested whether COR induces the necrotic phenotype in SlPrx-silenced tomato plants. Consistent with our observations in $N$. benthamiana, COR induced necrosis phenotype on Prx-silenced tomato plants (Fig. 2A). Because COI1/JAI1 is shown to be required for COR signaling in tomato and Arabidopsis (Feys et al. 1994; Katsir et al. 2008; Wangdi et al. 2010b), we transiently silenced SIPrx in jail mutant plants to determine whether or not the necrosis we observed in Prx-silenced tomato plants upon COR treatment is COII/JAII dependent. The Prx-silenced jail tomato plants showed no visible chlorosis or necrosis in response to exogenously applied COR (Fig. 2B), indicating that a COR-elicited necrosis phenotype in Prx- silenced tomato and $N$. benthamiana plants is dependent on COI1/JAI1-mediated signaling.

\section{Prx-silenced tomato plants show accelerated necrosis in response to $P$. syringae pv. tomato $\mathrm{DC} 3000$.}

To determine whether SlPrx affects disease symptoms induced by strain DC3000, we spray-inoculated vector control (TRV2::GFP) and Prx-silenced tomato plants with strain DC3000. The Prx-silenced tomato plants showed yellowish leaf coloration, which helped us select the plants with high efficiency of silencing, as further confirmed by the quantification of the endogenous transcript levels using qRT-PCR. Vector control plants developed typical bacterial specks with necrotic lesions surrounded by chlorotic halos (Fig. 3A). However, Prxsilenced plants developed accelerated (coalescing) necrotic lesions (Fig. 3A). Furthermore, the increased necrosis in strain DC3000-inoculated Prx-silenced plants was accompanied by a significant increase in ROS accumulation compared with the control (TRV2::GFP) plants (Fig. 3B). Interestingly, no sig-
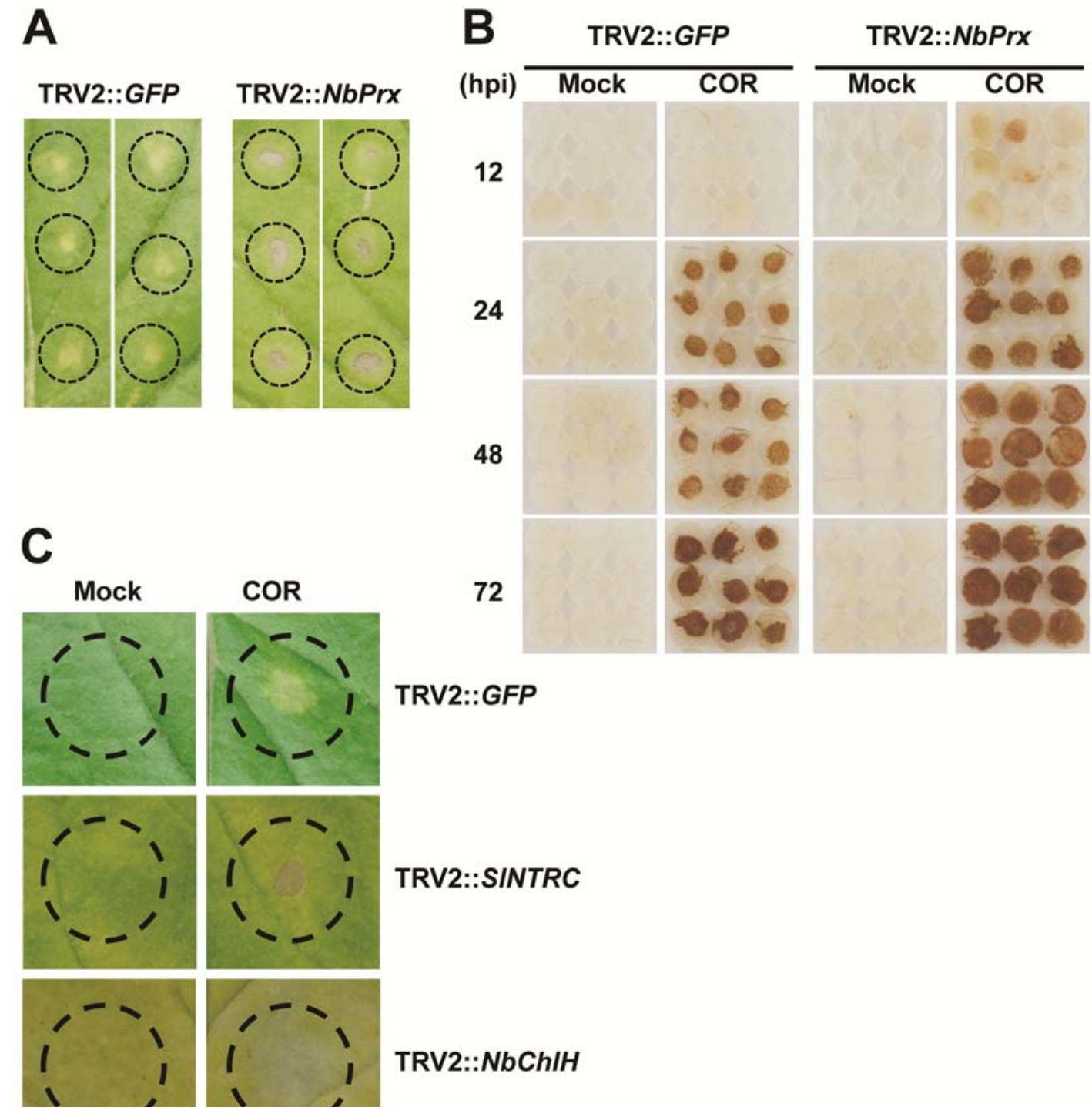

Fig. 1. Coronatine (COR) induces necrosis and reactive oxygen species $\left(\mathrm{H}_{2} \mathrm{O}_{2}\right)$ on peroxiredoxin $(P r x)$ - and NADPH-dependent thioredoxin reductase C $(N T R C)$-silenced Nicotiana benthamiana leaves. A, Purified COR was applied to vector control (TRV2::GFP) or Prx-silenced (TRV2::NbPrx) N. benthamiana leaves in $2-\mu \mathrm{l}$ aliquots $(2 \mathrm{nM})$ and a visible chlorotic zone or hypersensitive/necrotic cell death phenotype was recorded 4 days postinoculation (dpi). Phenotypes from three replicate treatments (marked circles) on each leaf from two independent silenced plants are shown. $\mathbf{B}$, $\mathrm{H}_{2} \mathrm{O}_{2}$ production in vector control (TRV2::GFP) or Prx-silenced (TRV2::NbPrx) N. benthamiana leaves in response to COR at 12, 24, 48, and 72 h postinoculation (hpi). Three leaf discs from independently silenced plants from two biological replicates are shown. $\mathbf{C}$, Chlorosis or necrosis phenotypes induced by COR on vector control (TRV2::GFP), NTRC (TRV2::NbNTRC)-, or CHlh (TRV2::NbChlH)-silenced $N$. benthamiana leaves in response to COR. Distilled water (2- $\mu$ l aliquots) was used as mock control. Photographs were taken 4 dpi with COR. 
nificant differences in bacterial multiplication were observed between the control and $\operatorname{Pr} x$-silenced plants at 3 and 6 days postinoculation (dpi) (Fig. 3C). However, higher bacterial multiplication was observed in $\operatorname{Pr} x$-silenced plants at $1 \mathrm{dpi}$, suggesting that Prx may function in an early step of basal defense (Fig. 3C). These results indicated that chloroplast-localized ROS contributes to the necrotic symptom development without altering the pathogen multiplication in tomato, and Prx may function as a negative regulator of disease-associated cell death.
Loss-of-function of NTRC in Arabidopsis and tomato results in accelerated necrotic cell death in response to $P$. syringae pv. tomato $\mathrm{DC} 3000$.

Previous results indicated that COR functions as an important virulence factor in tomato and Arabidopsis, although it functions differently in these hosts (Bent et al. 1992; Brooks et al. 2005; Uppalapati et al. 2007). To investigate the role of chloroplast ROS homeostasis in strain DC3000 disease development in Arabidopsis, we analyzed four individual T-DNA
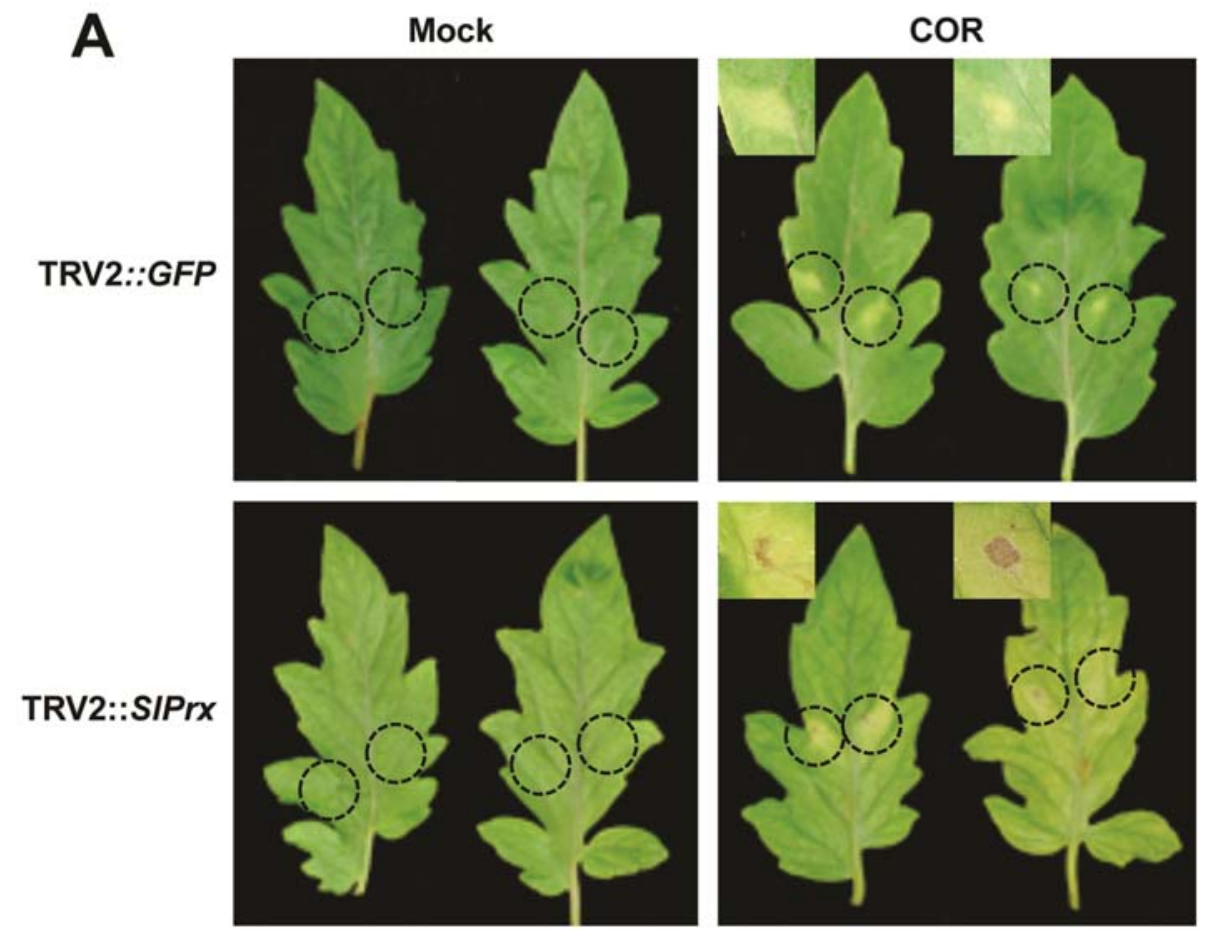

B

Mock
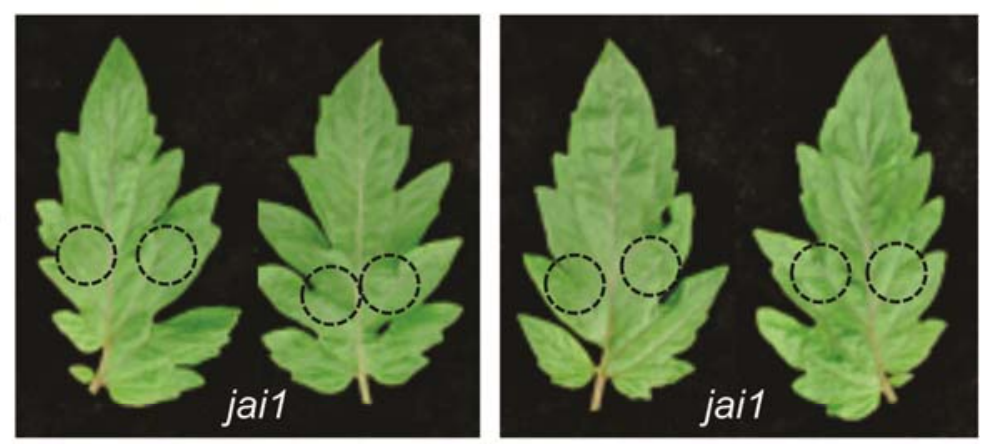

TRV2::GFP
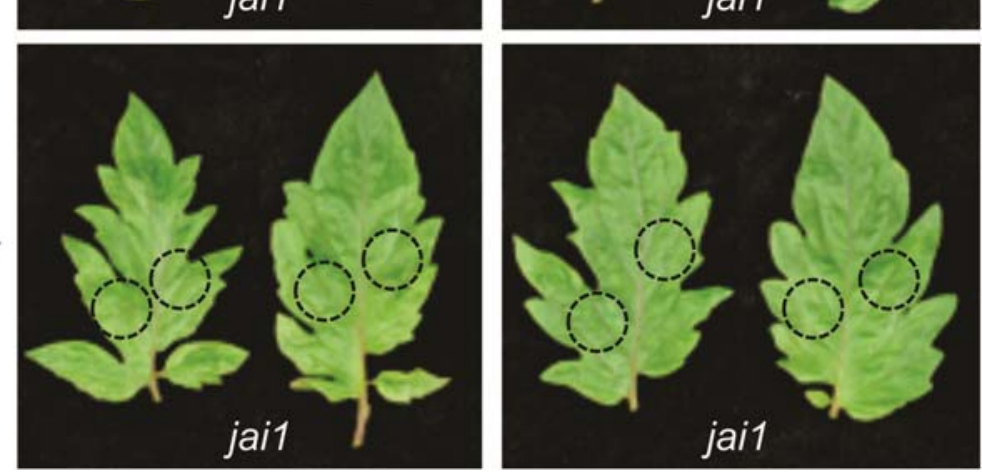

Fig. 2. Coronatine (COR)-insensitive 1 (COI1) is required for a COR-inducible necrosis phenotype on peroxiredoxin (Prx)-silenced tomato leaves. A, Purified COR elicits chlorosis on vector control (TRV2::GFP) plants and a necrosis phenotype on Prx-silenced (TRV2::SlPrx) tomato leaves. B, COR failed to induce chlorosis in jail/coil mutants (TRV2::GFP) or necrosis on Prx-silenced jasmonic acid-insensitive 1 (jail)/coil plants. COR was applied in 2 - $\mu 1$ aliquots $(2 \mathrm{nM})$ and a visible chlorotic zone or necrotic cell death phenotype was recorded 4 days postinoculation. Phenotypes from two replicates (marked circles) on each leaf from two independently silenced plants are shown. 
insertional mutants deficient in chloroplast-localized peroxiredoxins (PrxA, PrxB, PrxQ, and PrxIIE) and a T-DNA insertion mutant of $N T R C$, an electron donor for Prxs in the Trx system (Spinola et al. 2008). To test whether these prx and ntrc Arabidopsis mutants are loss-of-function alleles, the expression levels of respective genes were confirmed by semiquantitative
RT-PCR (Supplementary Fig. S6). Two-week-old Arabidopsis plants, including wild-type (Col-0), prx, and ntrc mutants grown on Murashige and Skoog (MS) agar, were dip-inoculated with strain DC3000 $\left(5 \times 10^{6} \mathrm{CFU} / \mathrm{ml}\right)$ and monitored for disease development. The wild-type Col-0 plants showed typical disease symptoms, consisting of chlorosis with water-soaked

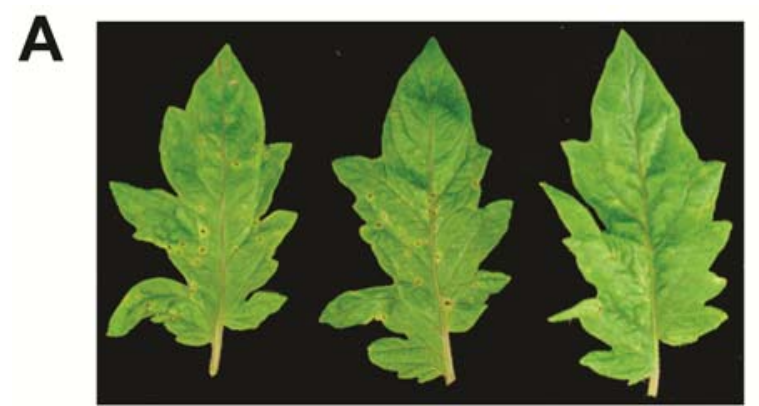

TRV2::GFP

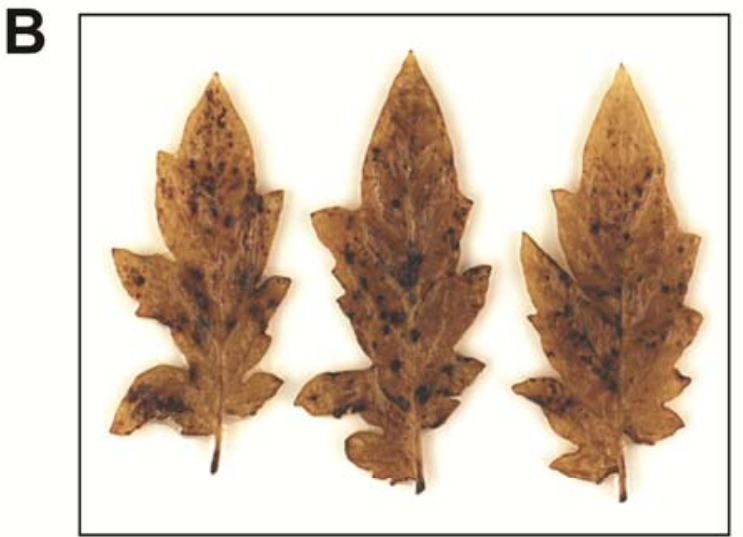

TRV2::GFP

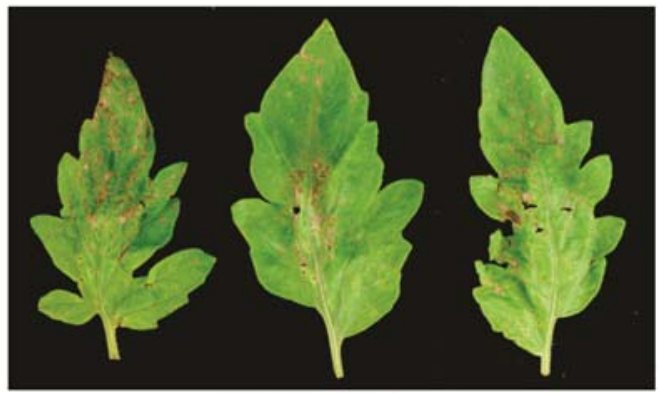

TRV2::NbPrx

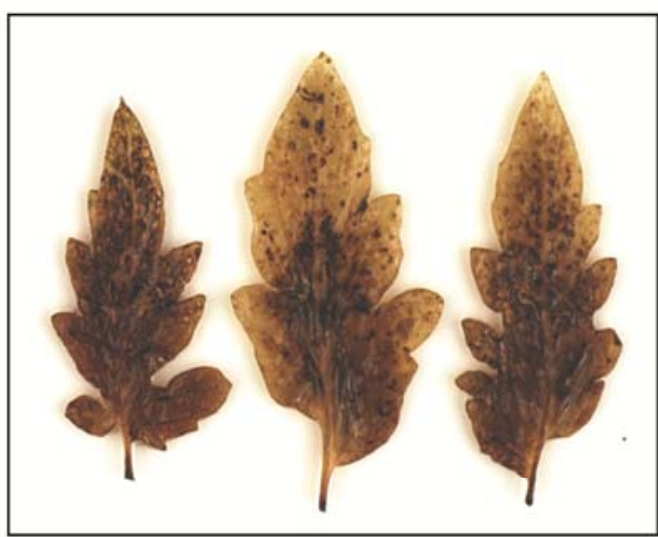

TRV2::NbPrx

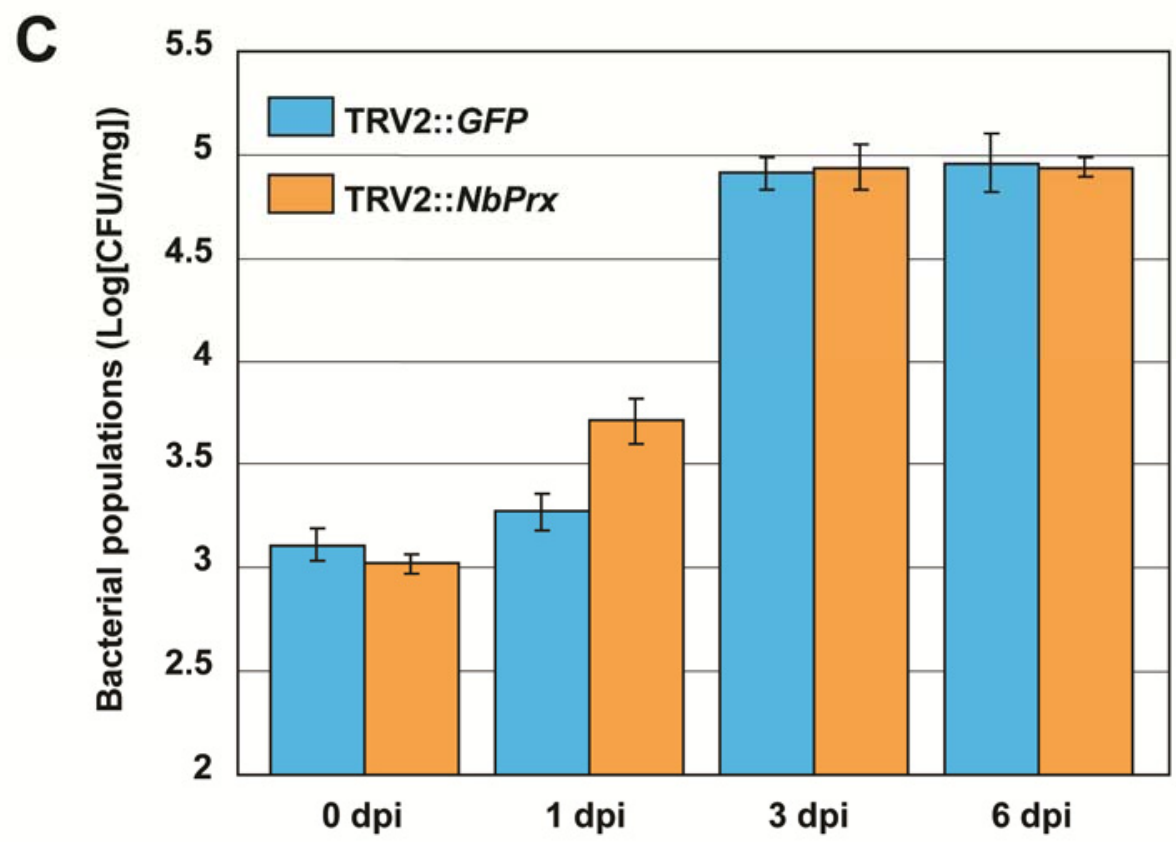

Fig. 3. Silencing of peroxiredoxin (Prx) (TRV2::SlPrx) in tomato leads to severe cell death with coalescing lesions in response to Pseudomonas syringae pv. tomato DC3000. A, Bacterial speck disease development; B, reactive oxygen species (ROS) accumulation visualized by staining hydrogen peroxide using 3,3'-diaminobenzidine; and C, in planta bacterial population numbers in vector control (TRV2::GFP) and Prx-silenced tomato (TRV2::SlPrx). Plants were spray inoculated to runoff with strain DC3000 at 2 to $5 \times 10^{7} \mathrm{CFU} / \mathrm{ml}$ in sterile distilled water containing $0.025 \%$ Silwet L77. Inoculated plants were observed for 7 days postinoculation (dpi) for symptom development. Bacterial growth was evaluated in three independent experiments at $0,1,3$, and 6 dpi. Disease phenotypes from three independent silenced plants are shown. Vertical bars indicate the standard error for three independent experiments. 

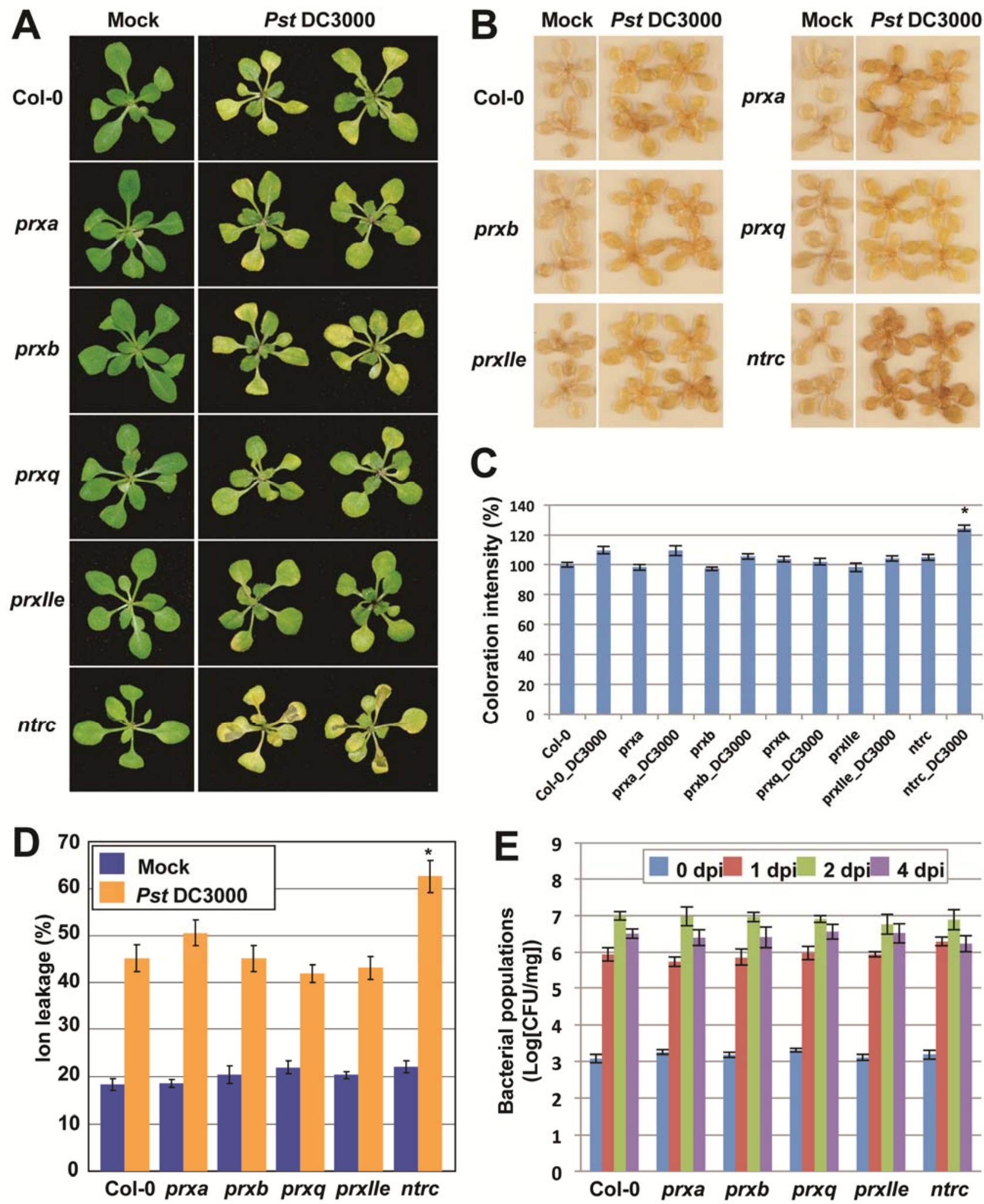

Fig. 4. Response of Arabidopsis peroxiredoxin ( prx) and NADPH-dependent thioredoxin reductase C (ntrc) mutant to Pseudomonas syringae pv. tomato DC3000 (Pst DC3000). A, Disease phenotype of Arabidopsis chloroplast-localized prx and ntrc mutants after dip-inoculation with strain DC3000 at $5 \times 10^{6}$ CFU/ml. Photographs were taken 2 days postinoculation (dpi). B, Hydrogen peroxide production in Arabidopsis chloroplast-localized prx and $n t r c$ mutants in response to strain DC3000. Reactive oxygen species (ROS) were visualized by staining hydrogen peroxide using 3,3'-diaminobenzidine, at 2 dpi. C, The intensity of DAB staining shown in panel B is quantified and expressed as percentage of coloration, where the color intensity of mock-treated wild-type (WT) Col-0 leaves was set at 100\%. Asterisks indicate a significant difference from WT Col-0 in a Student $t$ test (*<0.01). D, Ion leakage from Arabidopsis chloroplast-localized prx and ntrc mutants after treatment with water (mock) or inoculation with strain DC3000 at $5 \times 10^{6} \mathrm{CFU} / \mathrm{ml}$; measurements were taken 2 dpi. Values show the percentage of total ions. Vertical bars indicate the standard error for three independent experiments. Asterisks indicate a significant difference from WT Col-0 in a Student $t$ test $(*<0.01)$. E, Growth of strain DC3000 in Arabidopsis chloroplast-localized prx and ntrc mutants. Bacterial populations were obtained by surface sterilizing inoculated leaves, then plating dilutions to selective media 2 dpi. Vertical bars indicate the standard error for three independent experiments. 
lesions in response to strain DC3000 (Fig. 4A). Interestingly, individual mutations in any of the four chloroplastic prx genes (prxa, prxb, prxq, and prxIIe) did not significantly impact disease symptom development. These plants showed disease symp- toms typical of wild-type Col-0 plants (Fig. 4A). However, the ntrc mutant plants showed severe chlorosis and necrotic cell death in response to strain DC3000 when compared with the wild-type Col-0 plants (Fig. 4A). Furthermore, NTRC-overex-
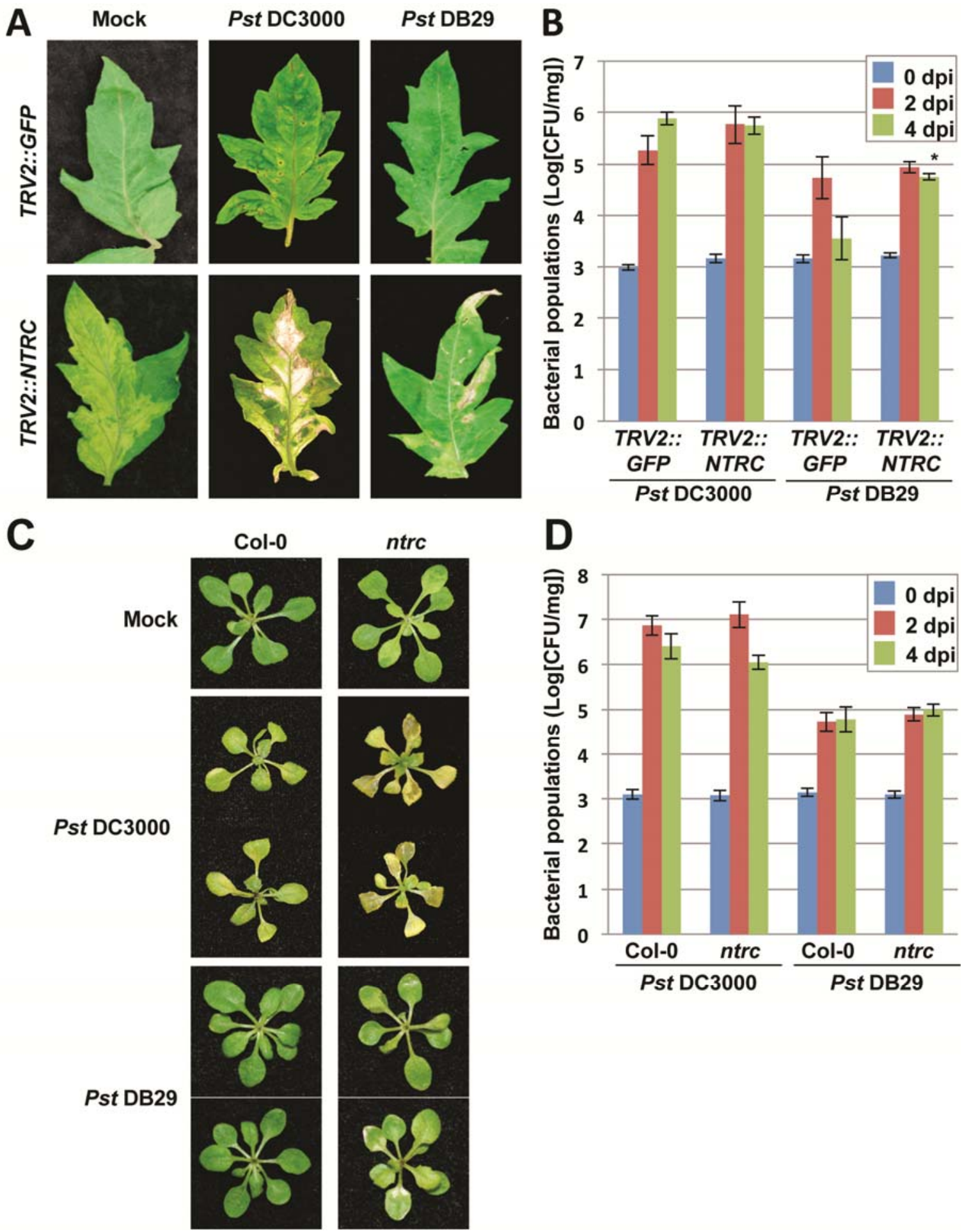

D

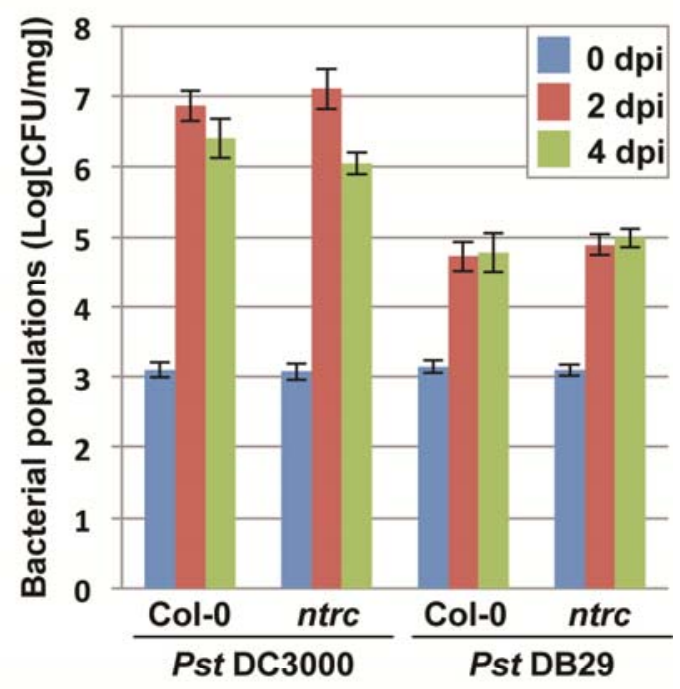

Fig. 5. Pseudomonas syringae pv. tomato DC3000 induces cell death in a coronatine (COR)-dependent manner in NADPH-dependent thiredoxin reductase (NTRC)-silenced tomato and ntrc mutants of Arabidopsis. A, Disease phenotype of vector control (TRV2::GFP) and NTRC-silenced (TRV2::SlNTRC) tomato plants spray-inoculated to runoff with strain DC3000 (Pst DC3000) or COR mutant P. syringae pv. tomato DB29 (Pst DB29) at $2 \times 10^{7}$ to $5 \times 10^{7}$ CFU/ml or with distilled water (Mock) containing $0.025 \%$ Silwet L-77. Photographs were taken 6 days postinoculation (dpi). B, In planta bacterial population numbers in vector control (TRV2::GFP) and NTRC-silenced tomato (TRV2::SlNTRC) plants spray-inoculated with strain DC3000 or DB29 in sterile distilled water. Bacterial growth was evaluated in three independent experiments at 0,2 , and 4 dpi. Vertical bars indicate the standard error for three independent experiments. Asterisks indicate a significant difference between TRV2::GFP and TRV2::SlNTRC in a Student $t$ test (*<0.01). C, Disease phenotype of wild-type Col-0 and ntrc mutant plants after flood-inoculation with distilled water (Mock), strain DC3000, or DB29. Photographs were taken at 3 dpi. Phenotypes from three independent plants are shown. D, Growth of strain DC3000 or DB29 in Arabidopsis ntrc mutants evaluated at 0, 2, and 4 dpi. Vertical bars indicate the standard error for three independent experiments. 
pressing plants displayed typical disease symptoms similar to the wild-type Col-0 plants after inoculation with strain DC3000 (Supplementary Fig. S7).

To further investigate whether strain DC3000-induced necrotic cell death is associated with accelerated ROS, 3,3'-diaminobenzidine (DAB) staining was carried out to detect $\mathrm{H}_{2} \mathrm{O}_{2}$ in wild-type, prx, and ntrc mutants after dip inoculation with strain DC3000. The accumulation of $\mathrm{H}_{2} \mathrm{O}_{2}$ was detected in wild-type, prx, and ntrc mutants in response to strain DC3000 (Fig. 4B and C). No significant differences in $\mathrm{H}_{2} \mathrm{O}_{2}$ accumulation were observed between wild-type and prx mutants. However, a significantly higher level of ROS accumulation was observed in ntrc mutant plants compared with wild-type Col-0 and prx plants (Fig. 4B and C). Furthermore, consistent with increased necrosis, a higher level of ion leakage (an indicator of cell death) was observed in ntrc plants inoculated with strain DC3000 compared with the wild-type Col-0 and prx mutants plants (Fig. 4D). These results indicated that the chloroplast-generated ROS functions as a positive signal leading to cell death in ntrc mutants.

To determine whether the more severe disease symptoms in the ntrc mutant plants could be caused by increased bacterial populations, the bacterial populations were evaluated at 1,2 , and 4 dpi with strain DC3000. No significant differences were observed in the populations of strain DC3000 in prx mutants, the ntrc mutant, and wild-type Col-0 plants (Fig. 4E). Taken together, these results suggested that chloroplast-generated ROS play a role in disease-induced cell death development in Arabidopsis, and NTRC functions as a negative regulator of pathogen-induced cell death by increased scavenging of the ROS in the healthy tissue surrounding the lesions.

We further investigated whether the accelerated diseaseassociated cell death in plants with altered ROS homoeostasis is dependent on COR-induced effects on the chloroplast. To this end, we inoculated NTRC-silenced tomato plants and ntrc mutant Arabidopsis plants with strain DC3000 and P. syringae pv. tomato DB29, a COR-defective mutant of strain DC3000. SINTRC silenced plants with a high level of silencing of endogenous SINTRC (as confirmed using qRT-PCR, which was used for inoculation assays). The vector control plant showed typical bacterial speck symptoms, consisting of necrotic lesions surrounded by chlorosis, within 7 days after spray inoculation with strain DC3000 (Fig. 5A), whereas NTRC-silenced plants showed severe necrotic cell death with coalescing lesions (Fig. 5A). Inoculation with COR-deficient strain DB29 failed to induce higher levels of cell death (necrosis) on NTRC-silenced plants. However, strain DB29 caused sporadic cell death (Fig. $5 \mathrm{~A}$ ) and multiplied higher in SINTRC-silenced plants compared with the vector control plants (Fig. 5B), indicating that NTRC has more generic effects on cellular redox associated with many biotic stresses. Furthermore, following flood inoculation, strain DB29 also failed to induce severe disease symptoms in wild-type and ntrc mutant seedlings of Arabidopsis (Fig. 5C). Interestingly, unlike tomato, strain DB29 did not multiply on $n t r c$ mutant plants (Fig. 5D). These results further demonstrated a role for COR-induced chloroplast-generated ROS in promoting disease-associated cell death in tomato and Arabidopsis.

\section{$P$. syringae pv. tomato DC3000 suppresses the expression of chloroplast-localized Prxs and NTRC in tomato and Arabidopsis.}

To further investigate the expression profiles of chloroplastlocalized Prxs and NTRC during strain DC3000-host interactions, we carried out the Northern blot analysis of these genes in tomato and Arabidopsis after inoculation with $P$. syringae pv. tomato DC3000 and COR-defective mutant strain DB29,
TTSS-defective hrcC mutant (Huang et al. 1992), or the exogenous application with $2 \mathrm{nM}$ of COR. In tomato plants, the expression of chloroplast-localized 2-Cys Prx, PrxQ, PrxIIE, and $N T R C$ was downregulated by strain DC3000 but not by strain DB29 (Fig. 6A). In addition, exogenous COR application strongly suppressed the expression of these genes in tomato (Fig. 6A), further confirming that strain DC3000 may manipulate chloroplast ROS homeostasis in a COR-dependent manner. The expression of NTRC was not suppressed in $h r c C$ mutant-inoculated tissue (Fig. 6B); however, slight suppression of 2-Cys Prx, PrxQ, and PrxIIE transcripts was observed at $24 \mathrm{~h}$ postinoculation (hpi) in $h r c C$ mutant-inoculated tissues compared with the mock-inoculated control (Fig. 6A). These results suggested that virulent (symptomatic) strain DC3000 but not strain DB29 or $h r c C$ downregulates NTRC and Prx genes.

In Arabidopsis plants, similar to tomato plants, strain DC3000 but not strain DB29 and $h r c C$ mutants suppressed the expression of chloroplast-localized 2-Cys $\operatorname{Pr} x$, PrxQ, PrxIIE, and NTRC

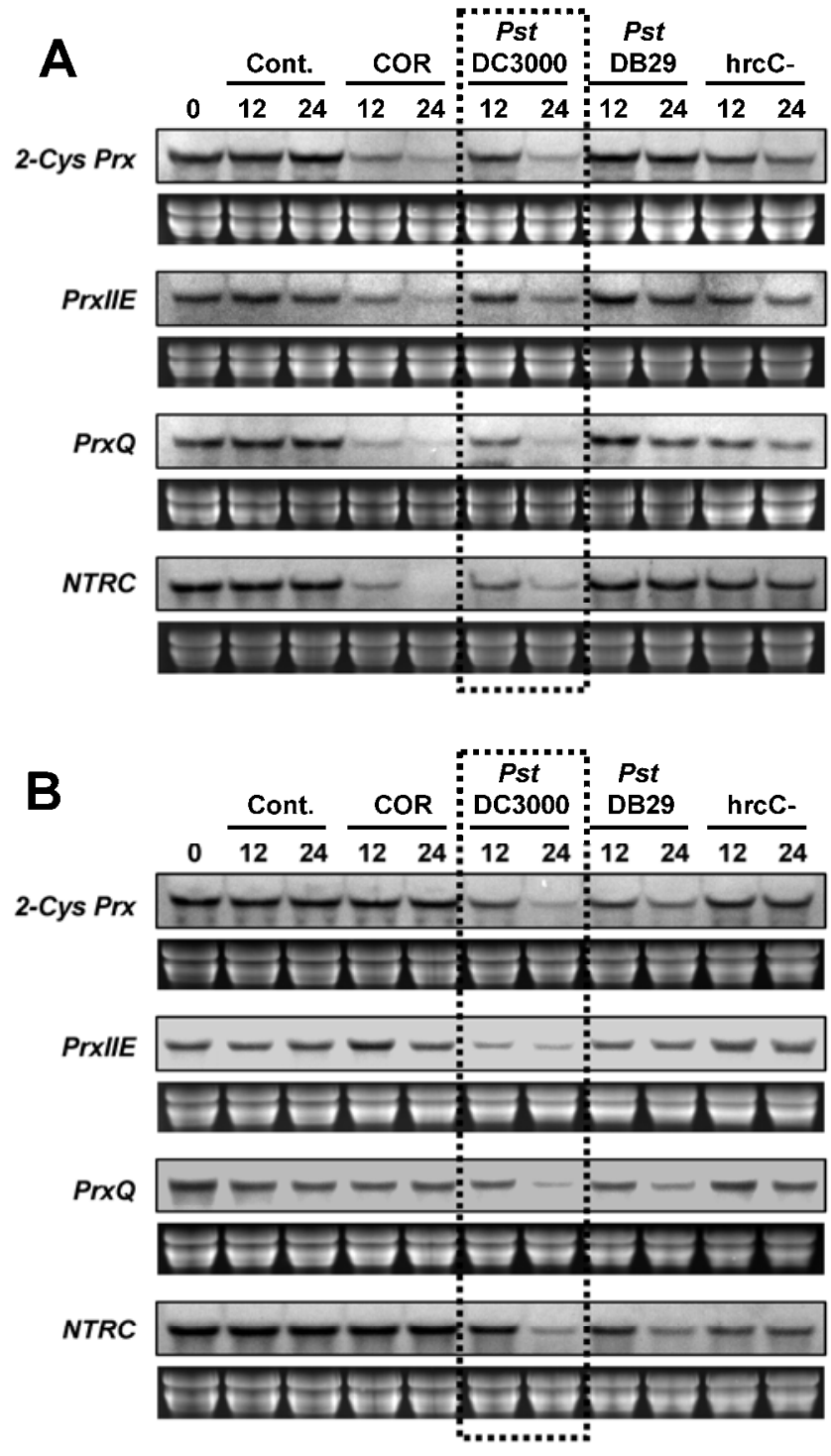

Fig. 6. Expression profiles of chloroplast-localized 2-Cys peroxiredoxin (Prxs), peroxiredoxin IIE (PrxIIE), PrxQ, and NADPH-dependent thioredoxin reductase $\mathbf{C}(N T R C)$ in $\mathbf{A}$, tomato and $\mathbf{B}$, Arabidopsis plants treated with water (control), coronatine (COR) (2 nM), or inoculated with Pseudomonas syringae pv. tomato DC3000 (Pst DC3000), COR mutant P. syringae pv. tomato strain DB29 (Pst DB29), or hrcC mutant. Total RNA (10 $\mu \mathrm{g}$ ) was analyzed, and ethidium bromide staining was used to show that the quality and equal quantity of RNA loaded on different blots. 
(Fig. 6B). Furthermore, unlike in tomato, authentic COR did not suppress the expression of 2-Cys Prx, PrxQ, PrxIIE, and NTRC at 12 and 24 hpi in Arabidopsis (Fig. 6B). Taken together, these results suggest that strain DC3000 may modulate chloroplast ROS homeostasis by downregulating the expression of genes encoding ROS-quenching enzymes, such as Prxs and NTRC.

\section{$N T R C$-silenced tomato plant shows accelerated necrotic cell death in response to $S$. sclerotiorum.}

Oxalic acid produced by $S$. sclerotiorum has been shown to induce ROS accumulation and elicit PCD during disease development (Kim et al. 2008). To further examine whether the chloroplast-generated ROS plays a general role in diseaseassociated necrotic cell death, we inoculated vector control and $N T R C$-silenced tomato plants with a necrotrophic fungal pathogen, $S$. sclerotiorum, and monitored disease symptom development. The $N T R C$-silenced plants showed accelerated necrotic cell death and disease symptoms compared with vectorcontrol plants (Fig. 7), indicating that chloroplast ROS may play a role in disease-associated cell death during tomato- $S$. sclerotiorum interactions.

\section{DISCUSSION}

In this study, altered chlorosis in response to COR led to the identification of a role for chloroplast ROS and a detoxification mechanism based on Prxs and NTRC in regulation of $P$. syringae pv. tomato DC3000 disease-associated cell death (Figs. 1 and 2). Furthermore, necrosis and $\mathrm{ROS}\left(\mathrm{H}_{2} \mathrm{O}_{2}\right)$ spread beyond the region of COR application (Fig. $1 \mathrm{~A}$ and $\mathrm{B}$ ), and spray inoculation of strain DC3000 on Prx- or NTRC-silenced tomato plants induced accelerated necrotic lesions similar to the runaway cell death phenotype reported earlier in the Arabidopsis acd1, acd2, and thf1 mutants (Greenberg and Ausubel 1993; Mach et al. 2001; Wangdi et al. 2010a). However, Prxor $N T R C$-silenced $N$. benthamiana plants showed no runaway
TRV2::GFP

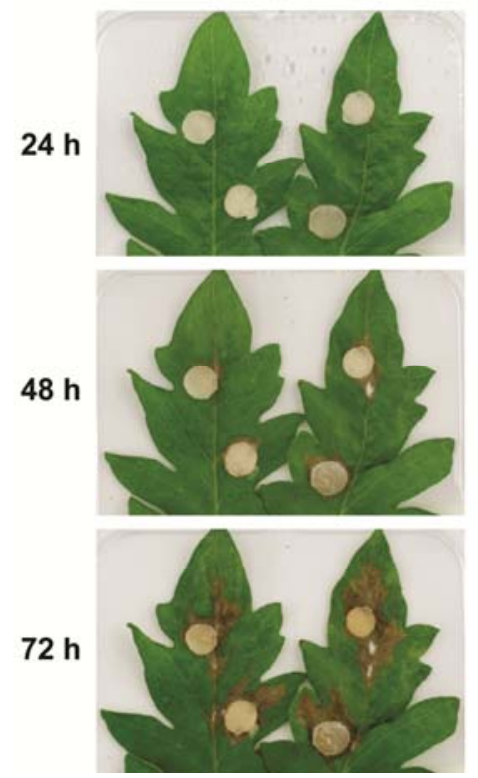

TRV2::SINTRC

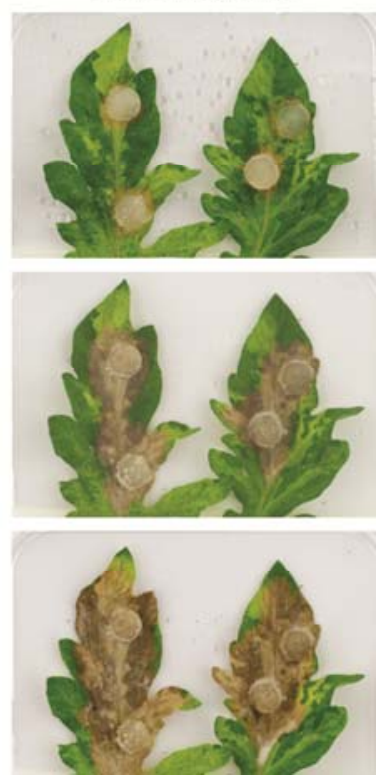

Fig. 7. Sclerotinia sclerotiorum disease symptoms on NADPH-dependent thioredoxin reductase $\mathrm{C}(N T R C)$-silenced tomato plants. Control (TRV2:: GFP) and $N T R C$-silenced (TRV2::SINTRC) plants were inoculated with potato dextrose agar plugs with actively growing $S$. sclerotiorum cultures. Inoculated plants were incubated at room temperature. Photographs were taken 24, 48, and $72 \mathrm{~h}$ postinoculation. Phenotypes from two replicate treatments (agar discs) on each leaf from two independent silenced plants are shown. cell death phenotype in response to HR-inducing nonhost pathogens and gene-for-gene interactions.

To further investigate the role of chloroplast ROS and a detoxification mechanism based on Prx and NTRC during host interactions, we chose Arabidopsis, because it is genetically tractable and is a host of strain DC3000. Mutations in any of the four individual chloroplast prx genes did not result in altered disease symptom development in response to host pathogen strain DC3000 (Fig. 4), suggesting that Arabidopsis Prxs function as redundant regulators of ROS homeostasis in the chloroplast. Consistently, Kirchesteiger and associates (2009) reported no phenotypic changes associated with the single TDNA insertional mutants of $\operatorname{Prx} A$ and $\operatorname{Prx} B$. Furthermore, a double mutant of $\operatorname{Pr} x A$ and $\operatorname{Prx} B(\Delta 2 \mathrm{cp}$ ) was also shown to have wild-type growth, suggesting that redox imbalance in these mutants can be compensated for by alternative chloroplast antioxidant systems or other members of the Prx family (Pulido et al. 2010). However, silencing of NbPrx (closet homologue of $\operatorname{Pr} x A$ and $\operatorname{Pr} x B$ ) via VIGS in $N$. benthamiana and tomato resulted in pale green leaves and necrosis phenotype upon COR application (Figs. 1 and 2), and strain DC3000-inoculated, Prx-silenced tomato plants also showed accelerated cell death and higher levels of $\mathrm{H}_{2} \mathrm{O}_{2}$ accumulation compared with the control plants (Fig. 3). Deficiencies of multiple members of $\operatorname{Prx}$ were required to see any significant affects of Prx in pathogen-associated cell death. Furthermore, based on VIGS analysis, we could not determine which members of Prx are specifically involved in chloroplast ROS homeostasis. Therefore, in this study, we focused on NTRC, an NADPH thioredoxin reductase that plays a central role in redox regulation (Pulido et al. 2010). Interestingly, an Arabidopsis knockout mutant of NTRC showed accelerated necrotic cell death in response to strain DC3000 (Fig. 4). NTRC contains an NADP-thioredoxin reductase (NTR) and a Trx domain in a single polypeptide chain and uses NADPH in detoxifying $\mathrm{H}_{2} \mathrm{O}_{2}$ via Prx (Pulido et al. 2010; Spinola et al. 2008). An Arabidopsis ntrc mutant has been shown to have pale green leaves associated with reduced chlorophyll contents, abnormal chloroplast structure, and unbalanced redox state (Lepisto et al. 2009; Perez-Ruiz et al. 2006). Furthermore, NTRC was demonstrated to be required for protection against oxidative damage, especially in low light and prolonged darkness (PerezRuiz et al. 2006), and was shown to play a more important role in chloroplast Prx reduction than Trx (Pulido et al. 2010). Consistent with the previous studies that show NTRC to be critical for redox regulation, here, we demonstrated a role for NTRC in regulation of pathogen-associated cell death, possibly via increased accumulation of chloroplast-generated ROS $\left(\mathrm{H}_{2} \mathrm{O}_{2}\right)$ in $n t r c$ mutants (Fig. 4). Overexpression of NTRC did not alter bacterial multiplication or disease symptom development in Arabidopsis. Consistent with our findings, overexpression of NTRC did not alter sensitivity to prolonged darkness (PerezRuiz et al. 2006). However, unlike the phenotype shown by the overexpression of NTRC in this study, the enhancement of oxidative stress tolerance in transgenic plants overexpressing ascorbate peroxidase (APX) has been reported (Badawi et al. 2004; Murgia et al. 2004). Furthermore, overexpression of Gentiana triflora $\operatorname{Pr} x Q$ was shown to impart resistance against both oxidative stress and fungal disease (Kiba et al. 2005). It is important to note that, unlike APX and PrxQ, NTRC functions as a central redox regulator in Prx-based detoxification system. Moreover, Pérez-Ruiz and associates (2006) reported that, although more transcripts of $N T R C$ were detected in $N T R C$-overexpressing Arabidopsis plants, the amount of NTRC proteins was similar with the wild type (Perez-Ruiz et al. 2006). Therefore, it is tempting to speculate that the protein level of NTRC might be tightly controlled by posttranscriptional regulation. 
Taken together with this study, there is increasing evidence for the role of chloroplast-generated ROS in HR or diseaseassociated cell death. In support of our results, a recent study demonstrated the requirement of chloroplast-generated ROS for HR cell death using tobacco plants expressing a chloroplast-targeted cyanobacterial flavodoxin, which functions as a general antioxidant to prevent the formation of ROS in chloroplasts (Zurbriggen et al. 2009). A chloroplastic ROS detoxification mechanism based on ferredoxin:thioredoxin reductase (FTR) was also shown to regulate PCD in tomato (Lim et al. 2010). Interestingly, unlike the phenotypes shown by the NTRC- or Prx-silenced plants in this study, Lim and associates (2010) showed that silencing of SlFTR-c results in spontaneous necrosis development even without the pathogen inoculation. Moreover, SIFTR- $c$-silenced plants showed enhanced resistance to $P$. syringae pv. tomato DC3000 when inoculated at a lower concentration of initial inoculum $\left(1 \times 10^{5} \mathrm{CFU} / \mathrm{ml}\right)$ (Lim et al. 2010). In the absence of FTR, $\mathrm{O}_{2}$ is the major acceptor of electrons from the photosynthetic electron transport. Thus, SlFTR-c-silenced plants overaccumulate chloroplast-generated ROS during general oxygenic photosynthesis, and these ROS serve as triggers of cell death and defense response before the onset of pathogen invasion. However, COR-induced effects on the photosynthetic machinery were required to create a metabolic imbalance in $P r x$ - or NTRC-silenced plants to generate higher levels of ROS that are sufficient to trigger disease-associated cell death. These observations suggested that chloroplast-generated ROS play a crucial role in localized lesion (cell death) development in a COR-dependent manner. In support of these observations, pretreatment of tomato seedlings with 3(3,4-dichlorophenyl)-1,1-dimethylurea, which inhibits photosynthetic electron transport and subsequent ROS generation, decreased the strain DC3000-induced necrotic symptoms (Ishiga et al. 2009a). It is important to note that reduction of Prx or NTRC by VIGS resulted in significantly accelerated disease-associated cell death accompanied by increased production of ROS in a COR-dependent manner, suggesting that the NTRC-mediated detoxification system functions as a crucial negative regulator of pathogen-induced cell death in the healthy tissue surrounding the lesions. Based on these results, it is tempting to speculate that cells that are in direct contact with COR produced by bacterial colonies in the infected leaves may produce sufficiently high rates of chloroplast-generated (sourced) ROS, resulting in localized cell death leading to lesion development. Furthermore, ROS are shown to play a role in regulating programmed cell death via MAPK pathways (Ren et al. 2002). Therefore, it remains to be tested whether the chloroplast-generated ROS may also serve as a signal to activate MAPKKK $\alpha$, a positive regulator of cell death induced by strain DC3000 in tomato (del Pozo et al. 2004).

In addition, $S G T 1 / S G T 1 b$ is shown to be required for CORinduced chlorosis and subsequent necrotic disease development in tomato and Arabidopsis (Uppalapati et al. 2010). However, $S G T 1$ was found to be a component of the COR/JA-mediated signal transduction pathway but not a component of the COI1 complex (Uppalapati et al. 2010). Taken together, these studies suggest that COI/SGT1-dependent COR-induced chlorosis generates ROS that trigger targeted cell death leading to lesion formation. Moreover, several effector proteins and PAMPs function through COI1- and JA-dependent pathways to promote virulence but not necessarily cell death during disease- or HR-associated PCD (Chang et al. 2000; DebRoy et al. 2004; Katou et al. 2005). In a previous report, it was demonstrated that the $N$. benthamiana jasmonate ZIM domain (JAZ) protein was related to PAMP-mediated signaling pathways leading to cell death. $N$. benthamiana JAZ proteins NtPPS1 and NtPPS3 were shown to be phosphorylated by PAMP-me- diated MAPK. NtPPS3 was also demonstrated to be efficient for cell death activated by an MAPK cascade (Katou et al. 2005). It is well-known that JAZ proteins are direct targets of the $\mathrm{SCF}^{\mathrm{COI} 1} \mathrm{E} 3$ ubiquitin-ligase, and JA or COR treatment induces their proteasome-mediated degradation, leading to release of the key transcriptional activator of JA responses, such as AtMYC2 (Chini et al. 2007; Thines et al. 2007). Furthermore, the COI1-JAZ complex was demonstrated to function as a receptor for JA or COR (Katsir et al. 2008). Based on these reports, we speculate that the COI1-JAZ complex or other components of JA or COR signaling pathways are related to both disease-associated cell death and HR cell death. Further characterization of targets for the chloroplast-generated ROS involved in disease-associated cell death and identification of plant signaling components targeted by COR and PAMPs are needed to understand the mechanisms of chloroplast-generated ROS-mediated redox signaling pathways leading to cell death.

In addition to COR, other virulence determinants, including effector proteins, are shown be involved in necrotic cell death associated with disease (Abramovitch and Martin 2004; Block and Alfano 2011; Chang et al. 2000; Cohn and Martin 2005; DebRoy et al. 2004; del Pozo et al. 2004; Munkvold et al. 2009). Interestingly, silencing of LeMAPKKK $\alpha$, a positive regulator of disease-associated cell death, is shown to reduce bacterial growth, suggesting that host-mediated cell death during the compatible interaction plays an important role in allowing full growth of $P$. syringae pv. tomato DC3000 (del Pozo et al. 2004). Therefore, our results, taken together with previous reports (Badel et al. 2006; Cohn and Martin 2005; del Pozo et al. 2004), raise some important questions on the mechanism or mechanisms of cell death elicitation during bacterial speck disease and the significance of host-mediated cell death during strain DC3000-associated cell death. It appears that host-cell (chloroplast)-death pathways may serve to remobilize nutrients into the apoplast by inducing senescence. It is tempting to speculate that several of the effectors may target chloroplast and highjack components of host-mediated cell death pathways to favor virulence, whereas chloroplast-generated ROS may serve as one of the components in triggering PCD associated with compatible interactions and leaf senescence (Quirino et al. 2000; Zapata et al. 2005). Therefore, it is tempting to speculate that chlorosis (or senescence) or localized cell death induced by COR may help to remobilize nutrients into the apoplast to help bacteria achieve full growth during the necrogenic phase of the hemibiotrophic pathogen, strain DC3000. In support of our hypothesis, it has been shown that $P$. syringae has acquired genes or pathways to assimilate a wide range of metabolites corresponding to those abundantly present in the apoplast of healthy plants and those that accumulate in plants during biotic and abiotic stress and senescence (Rico and Preston 2008).

Furthermore, taken together with previous reports, our results further support a central role for chloroplasts in disease development and as a major target for virulence determinants (e.g., COR and Hop1) of strain DC3000 (Guttman et al. 2002; Ishiga et al. 2009b; Jelenska et al. 2007, 2010; Munkvold et al. 2009; Uppalapati et al. 2010; Wangdi et al. 2010b). Further identification of other effectors that target chloroplasts and characterization of their mode of action in conjunction with COR and targets for the chloroplast-generated ROS are needed to understand the mechanisms of chloroplast-generated ROS in disease-associated cell death.

\section{MATERIALS AND METHODS}

Plant materials, bacterial strains, and inoculation methods. Nicotiana benthamiana and tomato (Solanum lycopersicum 'Glamour') plants were maintained in the greenhouse under a 
photoperiod with $14 \mathrm{~h}$ of light and $10 \mathrm{~h}$ of darkness at $25 \pm 2{ }^{\circ} \mathrm{C}$. Arabidopsis thaliana homozygous T-DNA insertion mutants deficient in PrxA (At3g11630; CS875813), PrxB (At5g06290; SALK_017213), PrxQ (At3g26060; SALK_070860), and PrxIIE (At3g52960; SALK_064512) were identified from the SALK Institute's collection by PCR analysis of genomic DNA according to the recommended protocols, and the expression levels of respective genes were confirmed by semiquantitative RT-PCR. Seed of the Arabidopsis ntrc T-DNA mutant, its complemented lines, and overexpression lines (Perez-Ruiz et al. 2006) were kindly provided by F. J. Cejudo (Instituto de Bioquímica Vegetal y Fotosíntesis, Spain). The homozygous lines of NTRC were confirmed by PCR analysis of the genomic DNA and NTRC expression analysis using semiquantitative RT-PCR. Seeds of Arabidopsis lines were germinated and maintained on half-strength MS medium $(0.3 \%$ phytagel) with Gamborg vitamins (PhytoTechnologies Laboratories, Shawnee Mission, KS, U.S.A.) and used for inoculation assay 2 weeks after germination at $25^{\circ} \mathrm{C}$ with a light intensity of $200 \mu \mathrm{E} \mathrm{m} \mathrm{m}^{-2}$ $\mathrm{s}^{-1}$ and a photoperiod with $12 \mathrm{~h}$ of light and $12 \mathrm{~h}$ of darkness.

P. syringae pv. tomato DC3000 was used as the wild-type strain for virulence assays on tomato and Arabidopsis. The COR-defective mutant strain DB29 was previously described (Brooks et al. 2004) and was kindly provided by B. Kunkel (Washington University, St. Louis). The P. syringae pv. tomato strains DC3000 and DB29 were grown at $28^{\circ} \mathrm{C}$ on mannitolglutamate (MG) medium (Keane et al. 1970) containing antibiotics in the following concentrations: rifampicin, $50 \mu \mathrm{g} \mathrm{ml}^{-1}$; kanamycin, $25 \mu \mathrm{g} \mathrm{ml}^{-1}$; and spectinomycin, $25 \mu \mathrm{g} \mathrm{ml}^{-1}$ for 36 to $48 \mathrm{~h}$. Prior to inoculation, bacteria were suspended in $1 \mathrm{ml}$ of sterile distilled $\mathrm{H}_{2} \mathrm{O}$.

Pathogen inoculation assays on vector control and VIGSsilenced tomato were conducted as described (Uppalapati et al. 2007). Briefly, bacterial suspensions (optical density at 600 $\mathrm{nm}\left[\mathrm{OD}_{600}\right]=0.1=2$ to $5 \times 10^{7} \mathrm{CFU} / \mathrm{ml}$ ) were prepared in sterile distilled water containing $0.025 \%$ Silwet L-77 (OSI Specialties Inc., Danbury, CT, U.S.A.) and spray-inoculated to runoff. The inoculated plants were then incubated in growth chambers at approximately $100 \%$ relative humidity (RH) for the first $24 \mathrm{~h}$ and at approximately $70 \% \mathrm{RH}$ for the rest of the experimental period. High humidity was achieved by placing a cool mist humidifier (ReliOn, 2 gallons/day) in the growth chamber. The inoculated plants were observed for $7 \mathrm{dpi}$ for symptom development. Bacterial growth in leaves was measured by determining the internal bacterial populations. Prior to sampling, leaves were surface sterilized with $15 \% \mathrm{H}_{2} \mathrm{O}_{2}$ for 3 min to eliminate epiphytic bacteria and then washed with sterile distilled water. The leaves were then homogenized in sterile distilled water, and serial dilutions were plated onto MG medium containing antibiotics. The bacterial population at $0 \mathrm{dpi}$ was estimated from leaves harvested $1 \mathrm{hpi}$. Bacterial growth was evaluated in three independent experiments.

Arabidopsis seedlings were inoculated by a modified method in which plants grown on solid media plates, prepared with half-strength MS medium with Gamborg vitamins and $1 \%$ sucrose (pH 5.7 to 5.8 ) and solidified with $0.3 \%$ phytagel (Sigma-Aldrich, St. Louis) in deep petri plates $(100 \mathrm{~mm} \times 25$ $\mathrm{mm}$ ), were flooded with bacterial cells as described for tomato (Ishiga et al. 2011; Uppalapati et al. 2010). Briefly, Arabidopsis seedlings grown on half-strength MS solid media were flooded with bacterial suspension with an $\mathrm{OD}_{600}=0.02(5 \times$ $10^{6} \mathrm{CFU} / \mathrm{ml}$ ) that consisted of sterile distilled $\mathrm{H}_{2} \mathrm{O}$ containing $0.025 \%$ Silwet L-77 (OSI Specialties Inc.). To achieve uniform inoculation, the bacterial suspension was dispensed into the petri dishes until the seedlings were completely submerged, and the seedlings were exposed to bacterial cells for 2 to $3 \mathrm{~min}$ with gentle mixing. After the inoculum was discarded, petri dishes containing inoculated seedlings were sealed with $3 \mathrm{M}$ micropore $2.5-\mathrm{cm}$ surgical tape (3M, St. Paul, MN, U.S.A.) and were incubated for 2 to 3 days at $24^{\circ} \mathrm{C}$ with light intensity of 100 to $150 \mu \mathrm{E} \mathrm{m}^{-2} \mathrm{~s}^{-1}$ and 12-h light-and-dark photoperiod. Another set of seedlings was flooded with sterile water that served as a mock control. In each experiment, 36 to 48 seedlings were evaluated, and each experiment was repeated at least three times. For bacterial growth in leaves, Arabidopsis seedlings were surface sterilized with $5 \% \mathrm{H}_{2} \mathrm{O}_{2}$. The bacterial populations were evaluated using the methods described above for tomato.

\section{VIGS and Agrobacterium-mediated transient expression assay.}

Agrobacterium tumefaciens GV2260 containing pTRV1 and pTRV2 with gene of interest (e.g., pTRV2::GFP, pTRV2::Prx, pTRV ::NTRC, pTRV2::ChlH, and pTRV2::PDS) was grown overnight on Luria-Bertani (LB) medium containing antibiotics (rifampicin, $25 \mu \mathrm{g} / \mathrm{ml}$ and kanamycin, $50 \mu \mathrm{g} / \mathrm{ml}$ ) at $28^{\circ} \mathrm{C}$. Bacterial cells were harvested and resuspended in induction medium (10 mM MES, pH 5.5, and $200 \mu \mathrm{M}$ acetosyringone) and incubated at room temperature on an orbital shaker for $5 \mathrm{~h}$. The bacterial cultures containing pTRV1 and pTRV2 with the gene of interest were mixed in equal ratios $\left(\mathrm{OD}_{600}=0.5\right)$ and infiltrated into lower leaves using a 1-ml needleless syringe (Liu et al. 2002; Ryu et al. 2004). The infiltrated plants were maintained in the greenhouse and used for studies 15 to 21 days postinfiltration.

To analyze the impact of gene-for-gene or PAMP-mediated HR in wild-type, Prx, and NTRC-silenced plants, A. tumefaciens GV2260 containing 35S::Pto and 35S::AvrPto or 35S::INF1 were grown overnight on LB medium containing antibiotics (rifampicin, $25 \mu \mathrm{g} / \mathrm{ml}$ and kanamycin, $50 \mu \mathrm{g} / \mathrm{ml}$ ) at $28^{\circ} \mathrm{C}$. Bacterial cells were harvested and resuspended in induction medium and incubated at room temperature in an orbital shaker for $12 \mathrm{~h}$. For experiments in which Pto and AvrPto were coexpressed, Agrobacterium cultures carrying these plasmids were mixed in equal ratios $\left(\mathrm{OD}_{600}=0.8\right)$ and infiltrated into leaves using a 1-ml needleless syringe. Four days after infiltration, gene-for-gene mediated HR cell death was observed.

\section{Northern blot, real-time qRT-PCR and semiquantitative RT-PCR analyses.}

Total RNA extraction and real-time qRT-PCR were done as described previously (Uppalapati et al. 2008). Total RNA was treated with Turbo DNase (Ambion, Austin, TX, U.S.A.) to eliminate genomic DNA, and $5 \mu \mathrm{g}$ of DNase-treated RNA was reverse transcribed using Superscript III reverse transcriptase (Invitrogen Corp., Carlsbad, CA, U.S.A.) with oligo d(T)15-20 primers. The cDNA $(1: 20)$ was then used for RT-PCR or qRTPCR. qRT-PCR was performed using primers shown in Supplementary Table S1 with Power SYBR Green PCR master mix (Applied Biosystems, Foster City, CA, U.S.A.) with an ABI Prism 7900 HT sequence detection system (Applied Biosystems). The $N$. benthamiana and tomato Actin was used as internal control. To study the downregulation of transcripts in silenced plants, qRT-PCR primers that anneal outside the region targeted for silencing were used. Average cycle threshold values calculated using Sequence Detection Systems (version 2.2.2; Applied Biosystems) from triplicate samples were used to determine the fold expression relative to controls, whereas semiquantitative RT-PCR was performed using a thermal cycler using gene-specific primers. AtActin was used as internal control.

Northern blot analysis was carried out as described previously with slight modifications (Ishiga et al. 2009b). Total RNA was extracted using TRIzol (Sigma) according to the manufacturer's 
protocol. Total RNA (10 $\mu \mathrm{g})$ was denatured, fractionated by electrophoresis on a $1 \%$ agarose gel, and then blotted onto nylon membranes (Amersham BioScience, Uppsala, Sweden). Digoxigenin (DIG)-labeled DNA probes were made with DIG PCR Labeling Mix (Boehringer Mannheim, Mannheim, Germany) with gene-specific primer sets. Hybridization was performed at $65^{\circ} \mathrm{C}$ overnight in a solution containing $50 \mathrm{mM}$ Church buffer (pH. 7.2), $5 \times \mathrm{SSC}(1 \times \mathrm{SSC}$ is $0.15 \mathrm{M} \mathrm{NaCl}$ plus $0.015 \mathrm{M}$ sodium citrate), $0.1 \%$ laurylsarcosine, $7 \%$ sodium dodecyl sulfate (SDS), and 1\% blocking solution (Boehringer Mannheim). Final washes were at $65^{\circ} \mathrm{C}$ in a solution containing $0.5 \mathrm{X}$ SSC and $0.1 \%$ SDS. Hybridized mRNAs were detected with anti-DIG antibody conjugated with alkaline phosphatase (Boehringer Mannheim) and its color detection substrate, BCIP/NBT (Promega Corp.).

\section{Detection of hydrogen peroxide.}

The generation of hydrogen peroxide was detected using DAB staining as described previously (Ishiga et al. 2009b; Ueno et al. 2003). After application with $2 \mu \mathrm{l}$ of COR (1 mM) or inoculation with $P$. syringae, the leaves were placed in DAB-HCl $(\mathrm{pH} \mathrm{3.8)}$ at $1 \mathrm{mg} / \mathrm{ml}$. After incubation for $6 \mathrm{~h}$ at room temperature, chlorophyll was removed with $95 \%$ ethanol. DAB staining in the leaves was quantified using Image $\mathrm{J}$ software (version 1.44). The intensity of staining was expressed as percentage of coloration, where the intensity of coloration of mock-inoculated wild-type Col-0 was set to $100 \%$.

\section{Ion leakage measurements.}

Ion leakage was used as an indirect quantitative measure for disease-associated cell death. Ion leakage was measured as described previously (Ishiga et al. 2009b). Arabidopsis seedlings grown on MS phytagel plates inoculated with $P$. syringae were gently removed and agitated in $30 \mathrm{ml}$ of distilled water for $3 \mathrm{~h}$, and electroconductivity was measured using an ion conductivity meter (Orion 555A; Thermo Electron Corp., Marietta, $\mathrm{OH}$, U.S.A.). Plants were then autoclaved for $20 \mathrm{~min}$ to kill the cells and release total ions into the medium. Values relative to the whole ion content after autoclaving were used to express the percent ion leakage.

\section{ACKNOWLEDGMENTS}

We thank R. Allen and S.-K. Muthappa for reviewing the manuscript. This work was supported by the Samuel Roberts Noble Foundation and, in part, by a grant to S. R. Uppalapati from Oklahoma Center for Advancement of Science and Technology (PSB09-021).

\section{LITERATURE CITED}

Abramovitch, R. B., and Martin, G. B. 2004. Strategies used by bacterial pathogens to suppress plant defenses. Curr. Opin. Plant Biol. 7:356-364.

Badawi, G. H., Kawano, N., Yamauchi, Y., Shimada, E., Sasaki, R., Kubo, A., and Tanaka, K. 2004. Over-expression of ascorbate peroxidase in tobacco chloroplasts enhances the tolerance to salt stress and water deficit. Physiol. Plant. 121:231-238.

Badel, J. L., Shimizu, R., Oh, H. S., and Collmer, A. 2006. A Pseudomonas syringae pv. tomato avrE1/hopM1 mutant is severely reduced in growth and lesion formation in tomato. Mol. Plant-Microbe Interact. 19:99-111.

Bender, C. L., Stone, H. E., Sims, J. J., and Cooksey, D. A. 1987. Reduced pathogen fitness of Pseudomonas syringae pv. tomato Tn5 mutants defective in coronatine production. Physiol. Mol. Plant Pathol. 30:273-283.

Bender, C. L., Palmer, D. A., Penaloza-Vazquez, A., Rangaswamy, V., and Ullrich, M. 1998. Biosynthesis and regulation of coronatine, a nonhost-specific phytotoxin produced by Pseudomonas syringae. Subcell. Biochem. 29:321-341.

Bender, C. L., Alarcon-Chaidez, F., and Gross, D. C. 1999. Pseudomonas syringae phytotoxins: Mode of action, regulation, and biosynthesis by peptide and polyketide synthetases. Microbiol. Mol. Biol. Rev. 63:266292.
Bent, A. F., Innes, R. W., Ecker, J. R., and Staskawicz, B. J. 1992. Disease development in ethylene-insensitive Arabidopsis thaliana infected with virulent and avirulent Pseudomonas and Xanthomonas pathogens. Mol. Plant-Microbe Interact. 5:372-378.

Block, A., and Alfano, J. R. 2011. Plant targets for Pseudomonas syringae type III effectors: Virulence targets or guarded decoys? Curr. Opin. Microbiol. 14:39-46.

Brooks, D. M., Hernandez-Guzman, G., Kloek, A. P., Alarcon-Chaidez, F., Sreedharan, A., Rangaswamy, V., Penaloza-Vazquez, A., Bender, C. L., and Kunkel, B. N. 2004. Identification and characterization of a welldefined series of coronatine biosynthetic mutants of Pseudomonas syringae pv. tomato DC3000. Mol. Plant-Microbe Interact. 17:162-174.

Brooks, D. M., Bender, C. L., and Kunkel, B. N. 2005. The Pseudomonas syringae phytotoxin coronatine promotes virulence by overcoming salicylic acid-dependent defences in Arabidopsis thaliana. Mol. Plant Pathol. 6:629-639.

Chang, J. H., Rathjen, J. P., Bernal, A. J., Staskawicz, B. J., and Michelmore, R. W. 2000. avrPto enhances growth and necrosis caused by Pseudomonas syringae pv. tomato in tomato lines lacking either Pto or Prf. Mol. Plant-Microbe Interact. 13:568-571.

Chini, A., Fonseca, S., Fernandez, G., Adie, B., Chico, J. M., Lorenzo, O., Garcia-Casado, G., Lopez-Vidriero, I., Lozano, F. M., Ponce, M. R., Micol, J. L., and Solano, R. 2007. The JAZ family of repressors is the missing link in jasmonate signalling. Nature 448:666-671.

Cohn, J. R., and Martin, G. B. 2005. Pseudomonas syringae pv. tomato type III effectors AvrPto and AvrPtoB promote ethylene-dependent cell death in tomato. Plant J. 44:139-154.

DebRoy, S., Thilmony, R., Kwack, Y. B., Nomura, K., and He, S. Y. 2004. A family of conserved bacterial effectors inhibits salicylic acid-mediated basal immunity and promotes disease necrosis in plants. Proc. Natl. Acad. Sci. U.S.A. 101:9927-9932.

del Pozo, O., Pedley, K. F., and Martin, G. B. 2004. MAPKKKalpha is a positive regulator of cell death associated with both plant immunity and disease. EMBO (Eur. Mol. Biol. Organ.) J. 23:3072-3082.

Ellis, J., Dodds, P., and Pryor, T. 2000. The generation of plant disease resistance gene specificities. Trends Plant Sci. 5: 373-379.

Feys, B., Benedetti, C. E., Penfold, C. N., and Turner, J. G. 1994. Arabidopsis mutants selected for resistance to the phytotoxin coronatine are male sterile, insensitive to methyl jasmonate, and resistant to a bacterial pathogen. Plant Cell 6:751-759.

Gomez-Gomez, L., and Boller, T. 2002. Flagellin perception: A paradigm for innate immunity. Trends Plant Sci. 7:251-256.

Greenberg, J. T., and Ausubel, F. M. 1993. Arabidopsis mutants compromised for the control of cellular damage during pathogenesis and aging. Plant J. 4:327-341.

Greenberg, J. T., and Yao, N. 2004. The role and regulation of programmed cell death in plant-pathogen interactions. Cell Microbiol. 6:201-211.

Gust, A. A., Biswas, R., Lenz, H. D., Rauhut, T., Ranf, S., Kemmerling, B., Gotz, F., Glawischnig, E., Lee, J., Felix, G., and Nurnberger, T. 2007. Bacteria-derived peptidoglycans constitute pathogen-associated molecular patterns triggering innate immunity in Arabidopsis. J. Biol. Chem. 282:32338-32348.

Guttman, D. S., Vinatzer, B. A., Sarkar, S. F., Ranall, M. V., Kettler, G., and Greenberg, J. T. 2002. A functional screen for the type III (Hrp) secretome of the plant pathogen Pseudomonas syringae. Science 295:1722-1726.

Heath, M. C. 2000. Hypersensitive response-related death. Plant Mol Biol. 44:321-334.

Huang, H. C., He, S. Y., Bauer, D. W., and Collmer, A. 1992. The Pseudomonas syringae pv. syringae $61 \mathrm{hrpH}$ product, an envelope protein required for elicitation of the hypersensitive response in plants. J. Bacteriol. 174:6878-6885.

Ishiga, Y., Uppalapati, S.R., Ishiga, T., Elavarthi, S., Martin, B., and Bender, C.L. 2009a. Involvement of coronatine-inducible reactive oxygen species in bacterial speck disease of tomato. Plant Signal. Behav. 4:237-239.

Ishiga, Y., Uppalapati, S.R., Ishiga, T., Elavarthi, S., Martin, B., and Bender, C. L. 2009b. The phytotoxin coronatine induces light-dependent reactive oxygen species in tomato seedlings. New Phytol. 181:147-160.

Ishiga, Y., Ishiga, T., Uppalapati, S. R., and Mysore, K. S. 2011. Arabidopsis seedling flood-inoculation technique: A rapid and reliable assay for studying plant-bacterial interactions. Plant Methods 7:32.

Jelenska, J., Yao, N., Vinatzer, B. A., Wright, C. M., Brodsky, J. L., and Greenberg, J. T. 2007. A J domain virulence effector of Pseudomonas syringae remodels host chloroplasts and suppresses defenses. Curr. Biol. 17:499-508.

Jelenska, J., van Hal, J. A., and Greenberg, J. T. 2010. Pseudomonas syringae hijacks plant stress chaperone machinery for virulence. Proc. Natl. Acad. Sci. U.S.A. 107:13177-13182. 
Katou, S., Yoshioka, H., Kawakita, K., Rowland, O., Jones, J. D., Mori, H., and Doke, N. 2005. Involvement of PPS3 phosphorylated by elicitorresponsive mitogen-activated protein kinases in the regulation of plant cell death. Plant Physiol. 139:1914-19226.

Katsir, L., Chung, H. S., Koo, A. J., and Howe, G. A. 2008. Jasmonate signaling: A conserved mechanism of hormone sensing. Curr. Opin. Plant Biol. 11:428-435.

Keane, P. J., Kerr, A., and New, P. B. 1970. Crown gall of stone fruit II Identification and nomenclature of agrobacterium isolates. Aust. J. Biol. Sci. 23:585-596.

Kiba, A., Nishihara, M., Tsukatani, N., Nakatsuka, T., Kato, Y., and Yamamura, S. 2005. A peroxiredoxin Q homolog from gentians is involved in both resistance against fungal disease and oxidative stress. Plant Cell Physiol. 46:1007-1015.

Kim, K. S., Min, J. Y., and Dickman, M. B. 2008. Oxalic acid is an elicitor of plant programmed cell death during Sclerotinia sclerotiorum disease development. Mol. Plant-Microbe Interact. 21:605-612.

Kirchsteiger, K., Pulido, P., Gonzalez, M., and Cejudo, F. J. 2009. NADPH thioredoxin reductase $\mathrm{C}$ controls the redox status of chloroplast 2-Cys peroxiredoxins in Arabidopsis thaliana. Mol. Plant 2:298-307.

Kloek, A. P., Verbsky, M. L., Sharma, S. B., Schoelz, J. E., Vogel, J., Klessig, D. F., and Kunkel, B. N. 2001. Resistance to Pseudomonas syringae conferred by an Arabidopsis thaliana coronatine-insensitive (coi1) mutation occurs through two distinct mechanisms. Plant J. 26:509-522.

Lepisto, A., Kangasjarvi, S., Luomala, E. M., Brader, G., Sipari, N., Keranen, M., Keinanen, M., and Rintamaki, E. 2009. Chloroplast NADPH-thioredoxin reductase interacts with photoperiodic development in Arabidopsis. Plant Physiol. 149:1261-1276.

Lim, C. J., Kim, W. B., Lee, B. S., Lee, H. Y., Kwon, T. H., Park, J. M., and Kwon, S. Y. 2010. Silencing of SIFTR-c, the catalytic subunit of ferredoxin:thioredoxin reductase, induces pathogenesis-related genes and pathogen resistance in tomato plants. Biochem. Biophys. Res. Commun. 399:750-754

Liu, Y., Schiff, M., and Dinesh-Kumar, S. P. 2002. Virus-induced gene silencing in tomato. Plant J. 31:777-786.

Liu, Y., Schiff, M., Czymmek, K., Talloczy, Z., Levine, B., and DineshKumar, S. P. 2005. Autophagy regulates programmed cell death during the plant innate immune response. Cell 121:567-577.

Mach, J. M., Castillo, A. R., Hoogstraten, R., and Greenberg, J. T. 2001 The Arabidopsis-accelerated cell death gene ACD2 encodes red chlorophyll catabolite reductase and suppresses the spread of disease symptoms. Proc. Natl. Acad. Sci. U.S.A. 98:771-776.

Melotto, M., Underwood, W., Koczan, J., Nomura, K., and He, S. Y. 2006 Plant stomata function in innate immunity against bacterial invasion. Cell 126:969-980.

Munkvold, K. R., Russell, A. B., Kvitko, B. H., and Collmer, A. 2009 Pseudomonas syringae pv. tomato DC3000 type III effector HopAA1-1 functions redundantly with chlorosis-promoting factor PSPTO4723 to produce bacterial speck lesions in host tomato. Mol. Plant-Microbe Interact. 22:1341-1355.

Mur, L. A., Kenton, P., Lloyd, A. J., Ougham, H., and Prats, E. 2008. The hypersensitive response; the centenary is upon us but how much do we know? J. Exp. Bot. 59:501-520.

Murgia, I., Tarantino, D., Vannini, C., Bracale, M., Carravieri, S., and Soave, C. 2004. Arabidopsis thaliana plants overexpressing thylakoidal ascorbate peroxidase show increased resistance to Paraquat-induced photooxidative stress and to nitric oxide-induced cell death. Plant J. 38:940-953

Patel, S., and Dinesh-Kumar, S. P. 2008. Arabidopsis ATG6 is required to limit the pathogen-associated cell death response. Autophagy 4:20-27.

Perez-Ruiz, J. M., Spinola, M. C., Kirchsteiger, K., Moreno, J., Sahrawy, M., and Cejudo, F. J. 2006. Rice NTRC is a high-efficiency redox system for chloroplast protection against oxidative damage. Plant Cell 18:2356-2368.

Preston, G. M. 2000. Pseudomonas syringae pv. tomato: The right pathogen, of the right plant, at the right time. Mol. Plant Pathol. 1:263-275.

Pulido, P., Spinola, M. C., Kirchsteiger, K., Guinea, M., Pascual, M. B., Sahrawy, M., Sandalio, L. M., Dietz, K. J., Gonzalez, M., and Cejudo, F.J. 2010. Functional analysis of the pathways for 2-Cys peroxiredoxin reduction in Arabidopsis thaliana chloroplasts. J. Exp. Bot. 61:4043-4054

Quirino, B. F., Noh, Y. S., Himelblau, E., and Amasino, R. M. 2000. Molecular aspects of leaf senescence. Trends Plant Sci. 5:278-282.

Ren, D., Yang, H., and Zhang, S. 2002. Cell death mediated by MAPK is associated with hydrogen peroxide production in Arabidopsis. J. Biol. Chem. 277:559-565.

Rico, A., and Preston, G. M. 2008. Pseudomonas syringae pv. tomato DC3000 uses constitutive and apoplast-induced nutrient assimilation pathways to catabolize nutrients that are abundant in the tomato apoplast. Mol. Plant-Microbe Interact. 21:269-282.
Ryu, C. M., Anand, A., Kang, L., and Mysore, K. S. 2004. Agrodrench: A novel and effective agroinoculation method for virus-induced gene silencing in roots and diverse Solanaceous species. Plant J. 40:322-331.

Santner, A., and Estelle, M. 2009. Recent advances and emerging trends in plant hormone signalling. Nature 459:1071-1078.

Segonzac, C., and Zipfel, C. 2011. Activation of plant pattern-recognition receptors by bacteria. Curr. Opin. Microbiol. 14:54-61.

Senthil-Kumar, M., Hema, R., Anand, A., Kang, L., Udayakumar, M., and Mysore, K. S. 2007. A systematic study to determine the extent of gene silencing in Nicotiana benthamiana and other Solanaceae species when heterologous gene sequences are used for virus-induced gene silencing. New Phytol. 176:782-791.

Spinola, M. C., Perez-Ruiz, J. M., Pulido, P., Kirchsteiger, K., Guinea, M., Gonzalez, M., and Cejudo, F. J. 2008. NTRC new ways of using NADPH in the chloroplast. Physiol. Plant. 133:516-524.

Staswick, P. E., and Tiryaki, I. 2004. The oxylipin signal jasmonic acid is activated by an enzyme that conjugates it to isoleucine in Arabidopsis. Plant Cell 16:2117-2127.

Thines, B., Katsir, L., Melotto, M., Niu, Y., Mandaokar, A., Liu, G., Nomura, K., He, S. Y., Howe, G. A., and Browse, J. 2007. JAZ repressor proteins are targets of the $\mathrm{SCF}(\mathrm{COI} 1)$ complex during jasmonate signalling. Nature 448:661-665.

Ueno, M., Shibata, H., Kihara, J., Honda, Y., and Arase, S. 2003. Increased tryptophan decarboxylase and monoamine oxidase activities induce $\mathrm{Se}$ kiguchi lesion formation in rice infected with Magnaporthe grisea. Plant J. 36:215-228.

Uppalapati, S. R., Ayoubi, P., Weng, H., Palmer, D. A., Mitchell, R. E., Jones, W., and Bender, C. L. 2005. The phytotoxin coronatine and methyl jasmonate impact multiple phytohormone pathways in tomato. Plant J. 42:201-217.

Uppalapati, S. R., Ishiga, Y., Wangdi, T., Kunkel, B. N., Anand, A., Mysore, K. S., and Bender, C. L. 2007. The phytotoxin coronatine contributes to pathogen fitness and is required for suppression of salicylic acid accumulation in tomato inoculated with Pseudomonas syringae pv. tomato DC3000. Mol. Plant-Microbe Interact. 20:955-965.

Uppalapati, S. R., Ishiga, Y., Wangdi, T., Urbanczyk-Wochniak, E., Ishiga, T., Mysore, K. S., and Bender, C. L. 2008. Pathogenicity of Pseudomonas syringae pv. tomato on tomato seedlings: Phenotypic and gene expression analyses of the virulence function of coronatine. Mol. PlantMicrobe Interact. 21:383-395.

Uppalapati, S. R., Ishiga, Y., Ryu, C. M., Ishiga, T., Wang, K., Noel, L. D., Parker, J. E., and Mysore, K. S. 2010. SGT1 contributes to coronatine signaling and Pseudomonas syringae pv. tomato disease symptom development in tomato and Arabidopsis. New Phytol. 189:83-93.

Wan, J., Zhang, X. C., Neece, D., Ramonell, K. M., Clough, S., Kim, S. Y. Stacey, M. G., and Stacey, G. 2008a. A LysM receptor-like kinase plays a critical role in chitin signaling and fungal resistance in Arabidopsis. Plant Cell 20:471-481

Wan, J., Zhang, X. C., and Stacey, G. 2008b. Chitin signaling and plant disease resistance. Plant Signal. Behav. 3:831-833.

Wangdi, T., Uppalapati, S. R., Nagaraj, S., Ryu, C. M., Bender, C. L., and Mysore, K. S. 2010a. A role for chloroplast-localized thylakoid formation 1 (THF1) in bacterial speck disease development. Plant Signal. Behav. 5:425-427.

Wangdi, T., Uppalapati, S. R., Nagaraj, S., Ryu, C. M., Bender, C. L., and Mysore, K. S. 2010b. A virus-induced gene silencing screen identifies a role for thylakoid formation 1 in Pseudomonas syringae pv. tomato symptom development in tomato and Arabidopsis. Plant Physiol. 152:281-292.

Weiler, E. W., Kutchan, T. M., Gorba, T., Brodschelm, W., Niesel, U., and Bublitz, F. 1994. The Pseudomonas phytotoxin coronatine mimics octadecanoid signalling molecules of higher plants. FEBS (Fed. Eur. Biochem. Soc.) Lett. 345:9-13.

Zapata, J. M., Guera, A., Esteban-Carrasco, A., Martin, M., and Sabater, B. 2005. Chloroplasts regulate leaf senescence: Delayed senescence in transgenic ndhF-defective tobacco. Cell Death Differ. 12:1277-1284.

Zhang, J., and Zhou, J. M. 2010. Plant immunity triggered by microbial molecular signatures. Mol. Plant 3:783-793.

Zhao, Y., Thilmony, R., Bender, C. L., Schaller, A., He, S. Y., and Howe, G. A. 2003. Virulence systems of Pseudomonas syringae pv. tomato promote bacterial speck disease in tomato by targeting the jasmonate signaling pathway. Plant J. 36:485-499.

Zipfel, C. 2008. Pattern-recognition receptors in plant innate immunity. Curr. Opin. Immunol. 20:10-16.

Zurbriggen, M. D., Carrillo, N., Tognetti, V. B., Melzer, M., Peisker, M., Hause, B., and Hajirezaei, M. R. 2009. Chloroplast-generated reactive oxygen species play a major role in localized cell death during the nonhost interaction between tobacco and Xanthomonas campestris pv. vesicatoria. Plant J. 60:962-973. 